GAPP, número 24, noviembre de 2020

Sección: ESTUDIOS

Recibido: 24-10-2019

Modificado: 19-06-2020

Aceptado: $26-06-2020$

DOI: https://doi.org/10.24965/gapp.i24.10744

Páginas: 63-85

\title{
Impuestos sobre la riqueza y el ciclo político en el ámbito autonómico
}

\section{Wealth taxation in Spain and the political cycle at the regional level}

\author{
M. ${ }^{a}$ Ángeles Ortega Almón \\ Universidad de Granada (España) \\ ORCID: https://orcid.org/0000-0003-0374-637X \\ maortega@ugr.es
}

\section{NOTA BIOGRÁFICA}

Profesora Titular del Departamento de Economía Aplicada de la Universidad de Granada. Sus líneas de investigación se centran en el campo de la Economía del Sector Público, y más específicamente en: Empresa Pública y Privatizaciones; Financiación Autonómica; Impuestos medioambientales e Imposición sobre la riqueza.

\author{
Inmaculada Moreno Foronda \\ Fundación UGR Empresa (España) \\ inmamf@ugr.es
}

\section{NOTA BIOGRÁFICA}

Graduada en Economía, Máster en Dirección y Gestión Pública, Curso de Técnico en Gestión TributariaFiscal, Curso de Experto en Obligaciones Formales, Contables y Procedimentales Tributarias. Posición actual: Contrato de Formación por la Fundación UGR Empresa llevando a cabo la tarea de investigación sobre el mercado inmobiliario y su incidencia fiscal. Líneas de investigación: Sistema fiscal español.

Araceli Rojo Gallego-Burin

Universidad de Granada (España)

ORCID: https://orcid.org/0000-0001-8714-3693

gallegoburin@ugr.es

\section{NOTA BIOGRÁFICA}

Profesora de Economía Aplicada en la Universidad de Granada. Doctora en Ciencias Económicas y Empresariales por la Universidad de Granada. Acreditada como Profesora Contratada Doctora. Licenciada en Derecho, Administración y Dirección de Empresas e Investigación y Técnicas de Mercado. Sus líneas de investigación se centran en: imposición medioambiental y sobre la riqueza; la gestión de proveedores.

\section{RESUMEN}

En España, los impuestos que gravan la riqueza (excepto el IBI) están cedidos a las CC.AA, que tienen capacidad normativa para modificar los elementos básicos que determinan de la deuda tributaria del contribuyente (mínimos exentos, tipos impositivos o bonificaciones). Mientras que en algunas 
Comunidades, las bonificaciones propias aprobadas en la última década, han supuesto, en la práctica, la «supresión» de algunos de éstos tributos (por ejemplo, el Impuesto sobre el Patrimonio -IP- o el Impuesto sobre Sucesiones y Donaciones -ISD-) o disminución de los tipos impositivos (Impuesto sobre Transmisiones Patrimoniales y Actos Jurídicos Documentados -ITPAJD-), en otras Comunidades, se ha asistido a su «recuperación» o subida, muy unido en ambos casos, al ciclo político. Es decir, al uso de forma electoralista de las formas tributarias que gravan la riqueza.

En este trabajo se realiza una comparación, por CC.AA de Régimen Común, de la normativa propia, que afecta a los impuestos cedidos que gravan la riqueza, analizando los elementos determinantes de éstos, con el objetivo de contrastar su evolución durante los periodos pre-electorales y post-electorales, en función de la configuración política del Parlamento de cada Comunidad. Asimismo, se analiza el impacto que implica dichas modificaciones en la deuda tributaria de los contribuyentes, en función de su domicilio fiscal y del ciclo político.

\title{
PALABRAS CLAVE
}

Bonificaciones; IP; ISD; ITPAJD; Tipos impositivos; Ciclo político.

\begin{abstract}
In Spain, wealth taxes (except property tax) are transferred to the Autonomous Communities, which have the regulatory capacity to modify the basic determinants of the taxpayer's tax debt (exempt minimums, tax rates or tax credits). While in some Communities, the tax credits approved, in the last decade, have meant, in practice, the «suppression» of some of these taxes (eg, the Personal Wealth Tax or the Inheritance and Gift Tax) or a tax reduction (Tax on Capital Transfers and Documented Legal Acts), in other Communities, there has been a «recovery» or increase of them. Both cases have been closely linked to the political cycle. In other words, there has been an electoralist use of wealth taxes.

In this work, a comparison is made of the wealth taxes regulations in each Autonomous Community with the aim of analysing their evolution during the pre-electoral and post-electoral periods, taking into account the political configuration of each Autonomous Parliament. It also analyses the impact of these changes on taxpayers' tax debt, according to their tax domicile and the political cycle.
\end{abstract}

\section{KEYWORDS}

Tax credits; Wealth Tax; Inheritance and Gift Tax; Tax on Capital Transfers and Documented Legal Acts; Tax rates; Political Cycle.

\section{SUMARIO}

INTRODUCCIÓN. 1. UNA BREVE NOTA ACERCA DE LA POLÍTICA FISCAL Y EL CICLO POLÍTICO. 2. IMPUESTOS SOBRE LA RIQUEZA EN ESPAÑA Y ¿DESIGUALDADES TERRITORIALES? 2.1. IMPUESTO SOBRE EL PATRIMONIO Y DEUDA TRIBUTARIA DEL CONTRIBUYENTE POR CC.AA. 2.2. IMPUESTO SOBRE TRANSMISIONES PATRIMONIALES Y ACTOS JURÍDICOS DOCUMENTADOS Y DEUDA TRIBUTARIA POR COMUNIDADES. 2.3. IMPUESTO SOBRE SUCESIONES Y DONACIONES: ¿DESIGUALDADES TERRITORIALES? 3. CICLO POLÍTICO Y DEUDA TRIBUTARIA DE LOS IMPUESTOS SOBRE LA RIQUEZA CEDIDOS A LAS COMUNIDADES AUTÓNOMAS DE RÉGIMEN COMÚN. CONCLUSIONES. ANEXO I. REFERENCIAS BIBLIOGRÁFICAS.

\section{INTRODUCCIÓN}

La imposición sobre la riqueza engloba el conjunto de impuestos que, de una forma u otra, gravan el conjunto de bienes, derechos y obligaciones que componen el patrimonio de las personas. Es decir, recaen sobre el valor real de los activos reales y financieros y no sobre su rendimiento. Los impuestos sobre la riqueza gravan, fundamentalmente, la propiedad de patrimonio y su transmisión a título oneroso o gratuito, afectando de forma sensible a dos importantes objetivos económicos: la redistribución de la renta y de la riqueza y la formación de capital (Durán y Esteller, 2014). En el sistema tributario español existen cuatro impuestos que gravan la riqueza, estos son: el Impuesto de Bienes Inmuebles (IBI), gestionado por las Haciendas Lo- 
cales, el Impuesto de Patrimonio (IP), el Impuesto sobre Sucesiones y Donaciones (ISD) y del Impuesto de Transmisiones Patrimoniales y Actos Jurídicos Documentados (ITPAJD).

De estos tres últimos impuestos, las CC.AA tienen cedidas capacidades normativas y aspectos básicos y determinantes de la deuda tributaria (mínimos exentos, tipos impositivos, deducciones y bonificaciones), lo que está generando una disparidad normativa, así como notorias desigualdades entre los ciudadanos a la hora de tributar, según sea su lugar de residencia.

Por otro lado, la teoría del ciclo político-económico enfatiza en el hecho de que los gobernantes políticos hacen uso de todas las herramientas económicas de forma que resulten atractivas a los ciudadanos y que les permitan permanecer en el poder el mayor tiempo posible, en lugar de utilizar dichas herramientas para fomentar el crecimiento de la economía de un país. Los efectos de este tipo de actuaciones se convierten en políticas expansivas en los años de campaña (Bocchio, 2010). Como apunta William Nordhaus (1989), «La Teoría del Ciclo Político Económico, el cual analiza la interacción de los sistemas políticos y económicos, surge del hecho obvio de la vida donde los votantes se preocupan por la economía mientras que los políticos se preocupan por el poder».

El establecimiento de políticas económicas en los años de campaña electoral incluye, entre otras, reformas tributarias que afectan a todo el territorio español. Cada partido político aspirante al poder, puede establecer una serie de medidas fiscales que no tienen por qué seguir la misma línea que las que siguen los demás partidos. Los efectos de la persistente crisis económica de esta última década, junto con la caída de la recaudación provocada por ésta, unido todo ello a la necesidad de cumplir con el objetivo de déficit, ha llevado a algunas Comunidades a incrementar los tipos impositivos o reducir bonificaciones en la cuota en los tres impuestos analizados, al mismo tiempo que otras los disminuían o elevaban, dependiendo en ambos casos, de posibles intereses electoralistas provocados por los ciclos políticos.

El objetivo principal de este trabajo es analizar si existe una relación directa entre las modificaciones de los elementos determinantes de la deuda tributaria, de los impuestos sobre la riqueza que están cedidos a las Comunidades Autónomas de régimen común, y los periodos pre-electorales y post-electorales, de acuerdo con la configuración política del Parlamento de cada Comunidad Autónoma. Asimismo, se pretende analizar y comparar el resultado en la deuda tributaria de dichos impuestos condicionada por los tipos impositivos, bonificaciones y deducciones, propias de cada Comunidad, en función del lugar de residencia de los sujetos pasivos (contribuyentes), con el fin de demostrar las desigualdades territoriales que pueda generar su aplicación, y la posible competencia fiscal entre Comunidades, dependiendo del ciclo político. El periodo analizado se inicia en el año 2010, coincidiendo con la celebración de elecciones en Cataluña, hasta 2018.

Para alcanzar el objetivo anteriormente señalado, el trabajo se ha estructurado de la siguiente forma. En primer lugar, se realiza una breve exposición teórica de la política fiscal y el ciclo político. Seguidamente, se realiza una comparación en la evolución de la normativa propia de las CC.AA de Régimen Común, reflejada, en su impacto sobre la deuda tributaria de los impuestos que gravan la riqueza (IP, ISD y ITPYAJD), contrastando su evolución durante los periodos pre-electorales y post-electorales, en función de la configuración política del Parlamento de cada Comunidad. Para ello, se hace uso del planteamiento de «supuestos prácticos», en los que para el mismo hecho imponible, se calcula la deuda tributaria del sujeto pasivo, aplicando la normativa autonómica específica de cada impuesto, vigente en cada uno de los años analizados. Una vez estimada ésta, se compara el resultado, en función de la Comunidad de residencia de los contribuyentes. Con ello se trata de poner de manifiesto las diferentes cargas contributivas que un mismo contribuyente debe afrontar, por el mismo hecho imponible, según su domicilio fiscal. En el epígrafe 3, se lleva a cabo un estudio comparativo, donde se pretender comprobar la relación de los cambios políticos y la incidencia tributaria, reflejada en la deuda tributaria del contribuyente por Comunidades, según la configuración política del Parlamento autonómico. Para finalizar, se recogen las principales conclusiones.

Con el objetivo de que sean más visibles los resultados obtenidos en el cálculo de las deudas tributarias y su posible vinculación con los años pre-electorales y post-electorales, se ha sombreado en azul, en cada una de las tablas presentadas, los resultados de éstas, el año en el que se celebran elecciones autonómicas en cada Comunidad.

En el Anexo I, se recoge la composición parlamentaria de todas las CC.AA de régimen común, así como los gobiernos resultantes de las convocatorias de elecciones celebradas entre los años 2011 y 2018 . Asimismo, se muestra la composición parlamentaria de Cataluña tras las elecciones de dicha Comunidad en 2010.

Las principales fuentes de información que se ha utilizado para la elaboración de este trabajo son: la legislación estatal y autonómica, vigente cada año, de los impuestos analizados (IP, ITPYAJD e ISD), las 
páginas webs de las Consejerías de Hacienda de las distintas CC.AA de régimen común, las Memorias de la Administración Tributaria y de la Intervención General de la Administración del Estado, las Cuentas Generales de las CC.AA, así como, la web de la Junta Electoral Central (JEC).

\section{UNA BREVE NOTA ACERCA DE LA POLÍTICA FISCAL Y EL CICLO POLÍTICO}

Cuando se aproximan las elecciones, se suelen llevar a cabo medidas de política económica que permitan conseguir el mayor número de votos para el partido gobernante y hacer que este permanezca en el poder el mayor tiempo posible, así como utilizar instrumentos de política económica que ofrezcan resultados favorables a corto plazo para que los votantes vean a los partidos políticos como gestores prácticos (Nordhaus, 1975). Esto confirma la hipótesis fundamental de la escuela de la elección pública formulada por Downs A. (1957), «los partidos elaboran políticas para ganar las elecciones, en lugar de ganar las elecciones para poder formular políticas adecuadas». Los economistas denominan «ciclo político» a la política económica que siguen los gobiernos ante un proceso electoral.

Para los representantes políticos resulta más sencillo (y rentable en votos), manipular las variables presupuestarias, incrementando los presupuestos de gasto y rebajando los impuestos, justo antes de unas elecciones, constituyendo una estrategia potencialmente ventajosa, en lugar de fomentar un ciclo económico favorable mediante políticas fiscales y monetarias (Blais \& Nadeau, 1992). El hecho de reaccionar de esta manera por parte de los partidos políticos ofrece a la sociedad un falso Estado de Bienestar que incita a los ciudadanos a votarlos. Sin embargo, esos aumentos de gasto público y las reducciones de los impuestos no son, generalmente, beneficiosos para la economía de un país debido a la posible creación de inflación y aumento del déficit público, que luego han de ser subsanados en los años post-electorales (Beltran, 2004).

Normalmente, los años post-electorales son de ajuste y caída del PIB, por lo que se debe contraer la demanda y, esto puede crear un ritmo menor de crecimiento y un aumento de la tasa de desempleo. De esta manera, se concluye que los años posteriores a unas elecciones no son otra cosa que la recuperación de presupuesto de la etapa anterior a las elecciones, es decir, de los años pre-electorales. En los ciclos políticos, también resalta la aparición de la devaluación de las monedas en los años post-electorales, hecho que ningún partido político desea pero que, en ocasiones, surge irremediablemente, lo que puede llevar a asignar malas políticas económicas y desprestigio hacia los partidos políticos (Pampillón, 2006). No obstante, este último instrumento es inaplicable actualmente en el marco de la UE y de la Zona Euro.

En definitiva, el ciclo político-económico hace referencia a los efectos de las medidas de política económica ceñidas a eventos políticos sobre el comportamiento de la economía a corto plazo. Por lo que se sintetiza que la política económica, en cierto modo, se determina por el ciclo político, es decir, por la proximidad o lejanía de unas elecciones (Mejía, Reyes \& Rendón, 2017).

\section{IMPUESTOS SOBRE LA RIQUEZA EN ESPAÑA Y ¿DESIGUALDADES TERRITORIALES?}

En España, los impuestos sobre la riqueza cedidos a las Comunidades gravan el conjunto de bienes y derechos que forman parte del patrimonio de una persona física o jurídica, distinguiendo así entre: el Impuesto sobre el Patrimonio que grava la riqueza de forma global, el Impuesto sobre Transmisiones Patrimoniales y Actos Jurídicos Documentados que grava las transmisiones de riqueza inter vivos, las operaciones societarias y los actos jurídicos documentados y, el Impuesto sobre Sucesiones y Donaciones mediante el que se gravan todo tipo de incrementos patrimoniales que una persona puede obtener de forma gratuita, bien sea inter vivos o mortis causa. La recaudación de éstos está cedida a las CC.AA de régimen común que tienen asumidas competencias normativas importantes.

La cesión de capacidades normativas a las Comunidades, en aspectos básicos de estos Impuestos (mínimos exentos, tipos impositivos, deducciones y bonificaciones), está generando una disparidad normativa entre ellas. Ello implica que un mismo sujeto pasivo con una misma base liquidable tenga que afrontar una deuda tributaria diferente, en función de la Comunidad en la que tenga su domicilio fiscal.

Los siguientes sub-epígrafes tratan de mostrar a través del planteamiento de «supuestos prácticos», y aplicando la normativa autonómica específica de cada impuesto, vigente para cada año estudiado, cuál es la deuda tributaria que asumiría un mismo contribuyente en función de la Comunidad Autónoma de régimen común en la que se encuentre su domicilio fiscal. Asimismo, se analiza cómo evoluciona dicha deuda 
tributaria, desde el año 2010, que se celebran elecciones autonómicas en Cataluña, hasta el año 2018. El objetivo adicional es contrastar si el aumento o disminución de la deuda tributaria, en un año en concreto, puede estar relacionada con el ciclo político, es decir, si los cambios en la composición de los Parlamentos autonómicos han podido incidir sobre las variaciones que sufre ésta. En el Anexo I, se puede consultar por Comunidades, las fechas electorales y como han afectado al mapa político de cada Comunidad.

\subsection{Impuesto sobre el Patrimonio y deuda tributaria del contribuyente por CC.AA}

Con el propósito de analizar las diferencias que se producen en el pago del Impuesto sobre el Patrimonio al que se sometería un mismo sujeto pasivo sin discapacidad, en función de la Comunidad Autónoma en la que se produzca el hecho imponible del mismo, a continuación, se plantean dos «supuestos prácticos» que reflejan claramente la existencia de dichas desigualdades. Se calcula la evolución de la deuda tributaria de dicho sujeto pasivo en un período de tiempo de siete años, desde el año 2012 hasta el año $2018^{1}$, para cada una de las Comunidades Autónomas de régimen común.

Se parte del valor económico del patrimonio neto de un sujeto pasivo, una vez deducidas sus deudas pendientes (base liquidable), en la Comunidad en la que éste tenga establecido su domicilio fiscal. Se ha estimado $^{2}$ para dos bases imponibles diferentes, una para un Patrimonio Neto de $800.000 €$ y otra para un nivel de riqueza más elevado, de 4.000.000€.

En la tabla 1 se recogen los resultados obtenidos para el sujeto pasivo que dispone de un patrimonio neto de $800.000 €$, mientras que en la tabla 2 se encuentran los resultados obtenidos para el supuesto en el que el sujeto pasivo dispone de un patrimonio neto de 4.000.000€.

En el primer supuesto, en el que un sujeto pasivo dispone de un patrimonio neto de $800.000 €$, se observa que, en el año 2012, la cuantía de deuda tributaria a pagar oscila alrededor de los $200 €$ en todas las Comunidades Autónomas, a excepción de la Comunidad Valenciana, Baleares y Madrid, que siguen manteniendo la bonificación del $100 \%$ aplicada en toda España, durante el periodo 2008-2011. Aunque los sujetos pasivos cuya suma de bienes y derechos supere los 2.000 .000 de euros, en estas tres Comunidades, no tendrán que tributar, aunque sí presentar declaración. A partir de 2013, sólo Madrid mantiene dicha bonificación, suprimiéndose en Baleares y Valencia.

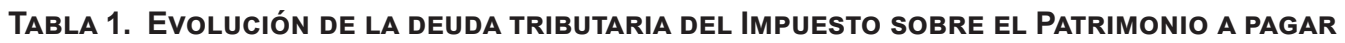
POR UN CONTRIBUYENTE CON UN PATRIMONIO NETO DE $800.000 €$ POR CC.AA (EN EUROS)

\begin{tabular}{lcccrrrr}
\hline CC.AA/AÑOS & $\mathbf{2 0 1 2}$ & $\mathbf{2 0 1 3}$ & $\mathbf{2 0 1 4}$ & $\mathbf{2 0 1 5}$ & $\mathbf{2 0 1 6}$ & $\mathbf{2 0 1 7}$ & $\mathbf{2 0 1 8}$ \\
\hline Andalucía & 220,00 & $\mathbf{2 4 0 , 0 0}$ & 240,00 & 240,00 & 240,00 & 240,00 & 240,00 \\
\hline Aragón & 200,00 & 200,00 & 200,00 & 200,00 & $\mathbf{6 0 0 , 0 0}$ & $\mathbf{1 . 1 6 4 , 4 1}$ & $1.164,41$ \\
\hline P. Asturias & 200,00 & $\mathbf{2 2 0 , 0 0}$ & 220,00 & 220,00 & 220,00 & 220,00 & 220,00 \\
\hline Baleares & 0,00 & $\mathbf{2 0 0 , 0 0}$ & 200,00 & $\mathbf{0 , 0 0}$ & $\mathbf{2 8 0 , 0 0}$ & 280,00 & 280,00 \\
\hline Canarias & 200,00 & 200,00 & 200,00 & 200,00 & 200,00 & 200,00 & 200,00 \\
\hline Cantabria & 200,00 & 200,00 & 200,00 & 200,00 & 200,00 & 200,00 & $\mathbf{2 4 0 , 0 0}$ \\
\hline C. León & 200,00 & 200,00 & 200,00 & 200,00 & 200,00 & 200,00 & 200,00 \\
\hline C.-La Mancha & 200,00 & 200,00 & 200,00 & 200,00 & 200,00 & 200,00 & 200,00 \\
\hline Cataluña & 200,00 & $\mathbf{7 6 9 , 5 1}$ & 769,51 & 769,51 & 769,51 & 769,51 & 769,51 \\
\hline
\end{tabular}

1 Para el Impuesto sobre el Patrimonio se analizan solo los años desde el 2012 hasta el 2018, un periodo temporal más corto que en los demás impuestos, debido a que este fue suprimido (sin ser eliminado) en el año 2008 por la Ley 4/2008, de 23 de diciembre. Es decir se aplicó una bonificación estatal del $100 \%$ de la cuota íntegra. En el año 2011 se libera, temporalmente, el IP para los próximos ejercicios mediante el Real Decreto-Ley 13/2011, de 16 de septiembre.

2 Cabe resaltar que la deuda tributaria de los sujetos pasivos por obligación personal (no real), está condicionada por la suma de las Cuotas Íntegras del IP y de las del IRPF (general y del ahorro). Para simplificar el cálculo de dicha deuda y que esta se vea de manera más nítida, se ha optado por estimarla en el caso, en el que se obtiene la cuota íntegra de este Impuesto, sin aplicar la reducción del IRPF. 
GAPP. Nueva Época - N. 24, noviembre 2020 - ISSN: 1989-8991 - DOI: https://doi.org/10.24965/gapp.i24.10744 - [Págs. 63-85]

Impuestos sobre la riqueza y el ciclo político en el ámbito autonómico M. ${ }^{a}$ Ángeles Ortega Almón / Inmaculada Moreno Foronda / Araceli Rojo Gallego-Burin

\begin{tabular}{|c|c|c|c|c|c|c|c|}
\hline CC.AA/AÑOS & 2012 & 2013 & 2014 & 2015 & 2016 & 2017 & 2018 \\
\hline Extremadura & 200,00 & 300,00 & 300,00 & 300,00 & 300,00 & $1.099,31$ & $1.099,31$ \\
\hline Galicia & 200,00 & 240,00 & 240,00 & 240,00 & 240,00 & 240,00 & 240,00 \\
\hline Madrid & 0,00 & 0,00 & 0,00 & 0,00 & 0,00 & 0,00 & 0,00 \\
\hline R. Murcia & 200,00 & 240,00 & 240,00 & 240,00 & 240,00 & 240,00 & 240,00 \\
\hline La Rioja & 200,00 & 200,00 & 200,00 & 100,00 & 100,00 & 100,00 & 50,00 \\
\hline C. Valenciana & 0,00 & 200,00 & 200,00 & 200,00 & 539,44 & 539,44 & 539,44 \\
\hline \multicolumn{8}{|c|}{$\begin{array}{l}\text { Notas: } \\
\text { - El sombreado azul indica que ese año se celebraron elecciones autonómicas en dicha Comunidad. } \\
\text { - El color rojo representa una subida de la deuda tributaria respecto al año anterior para un mismo hecho imponible, mientras } \\
\quad \text { que el color verde indica una reducción. }\end{array}$} \\
\hline
\end{tabular}

Fuente: Elaboración Propia.

A medida que van pasando los años, se observa que estas cantidades varían ligeramente en la mayoría de las Comunidades. En el año 2018 se constata que, únicamente cuatro, de las quince CC.AA de régimen común, obtienen una deuda tributaria a pagar superior a $500 €$, es decir, entre los $500 €$ y los $1.200 €$. El resto de Comunidades siguen oscilando entre los 200 y los 280 euros, cantidades no muy superiores a las del inicio del periodo de estudio (2012), mientras que en Madrid, el contribuyente no pagaría nada.

Sin embargo, para grandes patrimonios, como el ejemplo que se plantea, «un sujeto pasivo con un patrimonio neto de 4.000 .000 de euros», las cuantías de la deuda tributaria a las que tiene que hacer frente el mismo contribuyente son, además de lógicamente más elevadas, más fluctuantes a medida que pasa el tiempo. En el año 2012, el mismo sujeto pasivo pagaría lo mismo, prácticamente, en casi todas las Comunidades (36.546,37€), excepto en Madrid, Islas Baleares y Valencia, en la que la carga tributaria es cero. Ello es debido a que se mantiene en dichas Comunidades la bonificación del $100 \%$. Al final del periodo analizado, solo mantienen las cuantías iniciales cuatro Comunidades, el resto de ellas, modifican las cantidades a ingresar por la liquidación de este Impuesto. Estas variaciones se producen al alza, generando diferencias considerables en las cuantías de la deuda tributaria entre los contribuyentes según la Comunidad. En 2018, por ejemplo, en la Comunidad de Madrid, el sujeto pasivo no pagaría nada, mientras que su deuda tributaria si tuviera su domicilio fiscal en La Rioja, sería de 9.136,59€ (la bonificación del $50 \%$ aplicada desde 2015 en esta Comunidad, aumenta al $75 \%$, en 2018). Pero si el mismo contribuyente residiera en Extremadura, alcanzaría los 59.919,55€. Estas enormes diferencias provocan desigualdades territoriales entre los contribuyentes y disparidades en los poderes adquisitivos de cada uno de ellos, afectando, por tanto, al ahorro y la inversión.

TABLA 2. EVolución de LA DEUdA tRIBUtARIA Del IMPUESTO SOBRE EL PATRIMONIO A PAGAR POR UN CONTRIBUYENTE CON UN PATRIMONIO NETO DE 4.000.000€ POR CC.AA (EN EUROS)

\begin{tabular}{lccccccc}
\hline CC.AA/AÑOS & $\mathbf{2 0 1 2}$ & $\mathbf{2 0 1 3}$ & $\mathbf{2 0 1 4}$ & $\mathbf{2 0 1 5}$ & $\mathbf{2 0 1 6}$ & $\mathbf{2 0 1 7}$ & $\mathbf{2 0 1 8}$ \\
\hline Andalucía & $40.201,01$ & $\mathbf{4 4 . 2 1 4 , 8 2}$ & $44.214,82$ & $44.214,82$ & $44.214,82$ & $44.214,82$ & $44.214,82$ \\
\hline Aragón & $36.546,37$ & $36.546,37$ & $36.546,37$ & $36.546,37$ & $\mathbf{3 9 . 9 4 6 , 3 7}$ & $\mathbf{4 1 . 6 4 6 , 3 7}$ & $41.646,37$ \\
\hline P. Asturias & $36.546,37$ & $\mathbf{4 1 . 7 2 9 , 4 8}$ & $41.729,48$ & $41.729,48$ & $41.729,48$ & $41.729,48$ & $41.729,48$ \\
\hline Baleares & 0,00 & $\mathbf{3 6 . 1 5 5 , 2 9}$ & $36.155,29$ & $\mathbf{3 4 . 4 5 5 , 2 9}$ & $\mathbf{4 9 . 9 9 7 , 5 4}$ & $49.997,54$ & $49.997,54$ \\
\hline Canarias & $36.546,37$ & $36.546,37$ & $36.546,37$ & $36.546,37$ & $36.546,37$ & $36.546,37$ & $36.546,37$ \\
\hline Cantabria & $36.546,37$ & $36.546,37$ & $36.546,37$ & $36.546,37$ & $36.546,37$ & $36.546,37$ & $\mathbf{4 4 . 2 1 4 , 8 2}$ \\
\hline C. León & $36.546,37$ & $36.546,37$ & $36.546,37$ & $36.546,37$ & $36.546,37$ & $36.546,37$ & $36.546,37$ \\
\hline C.-La Mancha & $36.546,37$ & $36.546,37$ & $36.546,37$ & $36.546,37$ & $36.546,37$ & $36.546,37$ & $36.546,37$ \\
\hline Cataluña & $36.546,37$ & $\mathbf{4 1 . 9 4 3 , 6 9}$ & $41.943,69$ & $41.943,69$ & $41.943,69$ & $41.943,69$ & $41.943,69$ \\
\hline
\end{tabular}


GAPP. Nueva Época - N. 24, noviembre 2020 - ISSN: 1989-8991 - DOI: https://doi.org/10.24965/gapp.i24.10744 - [Págs. 63-85]

Impuestos sobre la riqueza y el ciclo político en el ámbito autonómico

M. ${ }^{a}$ Ángeles Ortega Almón / Inmaculada Moreno Foronda / Araceli Rojo Gallego-Burin

\begin{tabular}{|c|c|c|c|c|c|c|c|}
\hline CC.AA/AÑOS & 2012 & 2013 & 2014 & 2015 & 2016 & 2017 & 2018 \\
\hline Extremadura & $36.546,37$ & $54.819,56$ & $54.819,56$ & $54.819,56$ & $54.819,56$ & $59.919,55$ & $59.919,55$ \\
\hline Galicia & $36.546,37$ & $44.214,82$ & $44.214,82$ & $44.214,82$ & $44.214,82$ & $44.214,82$ & $44.214,82$ \\
\hline Madrid & 0,00 & 0,00 & 0,00 & 0.00 & 0.00 & 0.00 & 0,00 \\
\hline R. Murcia & $36.546,37$ & $43.855,64$ & $43.855,64$ & $43.855,64$ & $43.855,64$ & $43.855,64$ & $43.855,64$ \\
\hline La Rioja & $36.546,37$ & $36.546,37$ & $36.546,37$ & $18.273,19$ & $18.273,19$ & $18.273,19$ & $9.136,59$ \\
\hline C. Valenciana & 0,00 & $36.546,37$ & $36.546,37$ & $36.546,37$ & $47.646,32$ & $47.646,32$ & $47.646,32$ \\
\hline \multicolumn{8}{|c|}{$\begin{array}{l}\text { Notas: } \\
\text { - El sombreado azul indica que ese año se celebraron elecciones autonómicas en dicha Comunidad. } \\
\text { - El color rojo representa una subida de la deuda tributaria respecto al año anterior para un mismo hecho imponible, mientras } \\
\quad \text { que el color verde indica una reducción. }\end{array}$} \\
\hline
\end{tabular}

Fuente: Elaboración Propia.

Cabe destacar que en el Impuesto sobre el Patrimonio, los tipos impositivos oscilan entre el tipo mínimo estatal del $0,2 \%$ y el máximo del $2,5 \%$. Casi todas las Comunidades se acogen a la escala de gravamen estatal, siendo las principales diferencias que se aprecian entre ellas, consecuencia de la aplicación de bonificaciones en la cuota especificas aprobadas por cada Comunidad.

\subsection{Impuesto sobre Transmisiones Patrimoniales y Actos Jurídicos Documentados y deuda tributaria por Comunidades}

Con el objetivo de mostrar las diferencias más significativas que se producen en el pago del Impuesto sobre Transmisiones Patrimoniales y Actos Jurídicos Documentados, al que se sometería un mismo sujeto pasivo en función de la Comunidad Autónoma con competencia para recaudar éste y, su evolución en la misma Comunidad en el periodo analizado, a continuación, se plantea un supuesto práctico, seleccionando de las tres modalidades posibles del Impuesto, la que tiene una mayor incidencia recaudatoria de este tributo, Transmisiones Patrimoniales inter vivos.

Se parte del supuesto en el que «un ciudadano de 38 años adquiere su primera vivienda habitual de segunda mano, a un particular, con un valor real de 120.000 euros».

En la tabla 3 se recogen los tipos impositivos aplicados a las Transmisiones Patrimoniales de inmuebles, materializándose en la tabla 4, la estimación de la deuda tributaria que ha de afrontar el sujeto pasivo, según la Comunidad Autónoma.

Se puede observar que en el año 2010, todas las Comunidades Autónomas de régimen común tenían establecido el mismo tipo impositivo (7\%) para hacer frente al pago de la deuda tributaria en la modalidad de Transmisiones Patrimoniales de inmuebles, correspondiéndole una deuda tributaria de $8.400 €$. En definitiva, en el año 2010 no existían desigualdades territoriales impositivas en esta modalidad del ITPAJD entre las Comunidades.

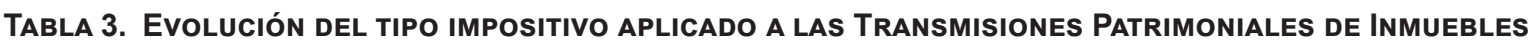
POR CC.AA DE RÉGIMEN COMÚN

\begin{tabular}{lrrrrrrrrr}
\hline CC.AA/Años & $\mathbf{2 0 1 0}$ & \multicolumn{1}{c}{$\mathbf{2 0 1 1}$} & $\mathbf{2 0 1 2}$ & $\mathbf{2 0 1 3}$ & $\mathbf{2 0 1 4}$ & $\mathbf{2 0 1 5}$ & $\mathbf{2 0 1 6}$ & $\mathbf{2 0 1 7}$ & $\mathbf{2 0 1 8}$ \\
\hline Andalucía & $7 \%$ & $7 \%$ & $\mathbf{8} \%$ & $8 \%$ & $8 \%$ & $8 \%$ & $8 \%$ & $8 \%$ & $8 \%$ \\
\hline Aragón & $7 \%$ & $7 \%$ & $7 \%$ & $7 \%$ & $7 \%$ & $7 \%$ & $\mathbf{8 \%}$ & $8 \%$ & $8 \%$ \\
\hline P. Asturias & $7 \%$ & $\mathbf{8} \%$ & $8 / \%$ & $8 \%$ & $8 \%$ & $8 \%$ & $8 \%$ & $8 \%$ & $8 \%$ \\
\hline Baleares & $7 \%$ & $7 \%$ & $7 \%$ & $\mathbf{8} \%$ & $8 \%$ & $8 \%$ & $8 \%$ & $8 \%$ & $8 \%$ \\
\hline Canarias & $6,5 \%$ & $6,5 \%$ & $6,5 \%$ & $6,5 \%$ & $6,5 \%$ & $6,5 \%$ & $6,5 \%$ & $6,5 \%$ & $6,5 \%$ \\
\hline
\end{tabular}


GAPP. Nueva Época - N. 24, noviembre 2020 - ISSN: 1989-8991 - DOI: https://doi.org/10.24965/gapp.i24.10744 - [Págs. 63-85]

Impuestos sobre la riqueza y el ciclo político en el ámbito autonómico M. ${ }^{a}$ Ángeles Ortega Almón / Inmaculada Moreno Foronda / Araceli Rojo Gallego-Burin

\begin{tabular}{|c|c|c|c|c|c|c|c|c|c|}
\hline CC.AA/Años & 2010 & 2011 & 2012 & 2013 & 2014 & 2015 & 2016 & 2017 & 2018 \\
\hline Cantabria & $7 \%$ & $7 \%$ & $7 \%$ & $8 \%$ & $8 \%$ & $8 \%$ & $8 \%$ & $8 \%$ & $10 \%$ \\
\hline C. León & $7 \%$ & $7 \%$ & $7 \%$ & $8 \%$ & $8 \%$ & $8 \%$ & $8 \%$ & $8 \%$ & $8 \%$ \\
\hline C.-La Mancha & $7 \%$ & $7 \%$ & $7 \%$ & $8 \%$ & $8 \%$ & $8 \%$ & $8 \%$ & $9 \%$ & $9 \%$ \\
\hline Cataluña & $7 \%$ & $8 \%$ & $8 \%$ & $8 \%$ & $10 \%$ & $10 \%$ & $10 \%$ & $10 \%$ & $10 \%$ \\
\hline Extremadura & $7 \%$ & $7 \%$ & $7 \%$ & $8 \%$ & $8 \%$ & $8 \%$ & $8 \%$ & $8 \%$ & $8 \%$ \\
\hline Galicia & $7 \%$ & $7 \%$ & $7 \%$ & $10 \%$ & $10 \%$ & $10 \%$ & $10 \%$ & $10 \%$ & $10 \%$ \\
\hline Madrid & $7 \%$ & $7 \%$ & $7 \%$ & $7 \%$ & $6 \%$ & $6 \%$ & $6 \%$ & $6 \%$ & $6 \%$ \\
\hline R. Murcia & $7 \%$ & $7 \%$ & $7 \%$ & $8 \%$ & $8 \%$ & $8 \%$ & $8 \%$ & $8 \%$ & $8 \%$ \\
\hline La Rioja & $7 \%$ & $7 \%$ & $7 \%$ & $7 \%$ & $7 \%$ & $7 \%$ & $7 \%$ & $7 \%$ & $7 \%$ \\
\hline C. Valenciana & $7 \%$ & $7 \%$ & $7 \%$ & $8 \%$ & $10 \%$ & $10 \%$ & $10 \%$ & $10 \%$ & $10 \%$ \\
\hline \multicolumn{10}{|c|}{$\begin{array}{l}\text { Notas: } \\
\text { - El sombreado azul indica que ese año se celebraron elecciones autonómicas en dicha Comunidad. } \\
\text { - El color rojo representa una subida de la deuda tributaria respecto al año anterior para un mismo hecho imponible, mientras } \\
\quad \text { que el color verde indica una reducción. }\end{array}$} \\
\hline
\end{tabular}

Fuente: Elaboración Propia.

Tabla 4. Deuda Tributaria a pagar por un sujeto pasivo en la modalidad de Transmisiones Patrimoniales DE INMUEBLES POR CC.AA DE RÉGIMEN COMÚN (EN EUROS)

\begin{tabular}{|c|c|c|c|c|c|c|c|c|c|}
\hline CC.AA/Años & 2010 & 2011 & 2012 & 2013 & 2014 & 2015 & 2016 & 2017 & 2018 \\
\hline Andalucía & 8.400 & 8.400 & 9.600 & 9.600 & 9.600 & 9.600 & 9.600 & 9.600 & 9.600 \\
\hline Aragón & 8.400 & 8.400 & 8.400 & 8.400 & 8.400 & 8.400 & 9.600 & 9.600 & 9.600 \\
\hline P. Asturias & 8.400 & 9.600 & 9.600 & 9.600 & 9.600 & 9.600 & 9.600 & 9.600 & 9.600 \\
\hline Baleares & 8.400 & 8.400 & 8.400 & 9.600 & 9.600 & 9.600 & 9.600 & 9.600 & 9.600 \\
\hline Canarias & 7.800 & 7.800 & 7.800 & 7.800 & 7.800 & 7.800 & 7.800 & 7.800 & 7.800 \\
\hline Cantabria & 8.400 & 8.400 & 8.400 & 9.600 & 9.600 & 9.600 & 9.600 & 9.600 & 12.000 \\
\hline C. León & 8.400 & 8.400 & 8.400 & 9.600 & 9.600 & 9.600 & 9.600 & 9.600 & 9.600 \\
\hline C.-La Mancha & 8.400 & 8.400 & 8.400 & 9.600 & 9.600 & 9.600 & 9.600 & 10.800 & 10.800 \\
\hline Cataluña & 8.400 & 9.600 & 9.600 & 9.600 & 12.000 & 12.000 & 12.000 & 12.000 & 12.000 \\
\hline Extremadura & 8.400 & 8.400 & 8.400 & 9.600 & 9.600 & 9.600 & 9.600 & 9.600 & 9.600 \\
\hline Galicia & 8.400 & 8.400 & 8.400 & 12.000 & 12.000 & 12.000 & 12.000 & 12.000 & 12.000 \\
\hline Madrid & 8.400 & 8.400 & 8.400 & 8.400 & 7.200 & 7.200 & 7.200 & 7.200 & 7.200 \\
\hline R. Murcia & 8.400 & 8.400 & 8.400 & 9.600 & 9.600 & 9.600 & 9.600 & 9.600 & 9.600 \\
\hline La Rioja & 8.400 & 8.400 & 8.400 & 8.400 & 8.400 & 8.400 & 8.400 & 8.400 & 8.400 \\
\hline C. Valenciana & 8.400 & 8.400 & 8.400 & 9.600 & 12.000 & 12.000 & 12.000 & 12.000 & 12.000 \\
\hline
\end{tabular}

Notas:

- El sombreado azul indica que ese año se celebraron elecciones autonómicas en dicha Comunidad.

- El color rojo representa una subida de la deuda tributaria respecto al año anterior para un mismo hecho imponible, mientras que el color verde indica una reducción. 
Sin embargo, en el año 2013 es en el que se producen más cambios, aumentándose así las cuantías de la deuda tributaria a pagar por los sujetos pasivos en más de la mitad de las CC.AA. Este hecho puede deberse a que el 2013 fue un año clave para comenzar a recuperar las pérdidas que se habían producido por la crisis económica que sufría España desde el año 2008 y, se pretendía corregir la brecha de recaudación que estos años habían provocado ${ }^{3}$.

No obstante, a medida que avanzan los años, los tipos impositivos van sufriendo modificaciones, llegando así al año 2018 en el que ninguna Comunidad Autónoma mantiene el $7 \%$ del año 2010, a excepción de La Rioja, consecuencia de los cambios notables que se han producido en todas ellas. En el año 2018 los tipos impositivos oscilan entre el $6 \%$ y el $10 \%$, aunque cabe mencionar que varias de las Comunidades (concretamente 7) apuestan por el tipo impositivo del $8 \%$. Las modificaciones de los tipos de gravamen provocan variaciones en las cuotas tributarias a pagar, variando éstas desde los $7.200 €$ hasta $12.000 €$. Ello es reflejo de la existencia de desigualdades, a las que ha de hacer frente, por el mismo hecho imponible un sujeto pasivo en función de la Comunidad en la que disponga su domicilio fiscal.

Estas diferencias, en principio, se pueden considerar como poco significativas, si se observa la tabla 3 , donde se recogen los tipos impositivos. No obstante, una variación porcentual de un punto significa, en nuestro ejemplo, un aumento a pagar por el contribuyente de $1.200 €$.

\subsection{Impuesto sobre Sucesiones y Donaciones: ¿desigualdades territoriales?}

Con la intención de conocer las notorias diferencias por CC.AA que se producen en el momento de la liquidación del pago de la deuda tributaria del Impuesto sobre Sucesiones y Donaciones, a continuación, se plantea un supuesto práctico a través del cual se visualizarán de manera directa dichas diferencias. Se parte del hipotético caso de sujetos pasivos con características idénticas (base imponible, edad, grupo de parentesco y patrimonio preexistente) que deben hacer frente al pago de este Impuesto en cada una de las CC.AA de régimen común, en el periodo temporal que se está analizando. En concreto, un Joven de 31 años que recibe una masa hereditaria neta de $800.000 €$ de su padre y contado el hijo con un patrimonio preexistente de $300.000 €$.

En este caso, se trata de una sucesión mortis causa de padre a hijo. Como el beneficiario es un hijo mayor de 21 años, pertenece al Grupo II de parentesco, por lo que para realizar y estudiar el supuesto es necesario tener en cuenta las características de dicho grupo.

En la tabla 5 se muestran los resultados estimados para dicho supuesto, una vez aplicada la normativa vigente en cada Comunidad.

TAbla 5. Deuda Tributaria a pagar por un SUjeto pasivo en la modalidad de sucesiones (MORTIS CAUSA) DEL IMPUESTO SOBRE SUCESIONES Y DONACIONES (EN EUROS)

\begin{tabular}{lcrrrrrrrr}
\hline CC.AA/AÑOS & \multicolumn{1}{c}{$\mathbf{2 0 1 0}$} & $\mathbf{2 0 1 1}$ & $\mathbf{2 0 1 2}$ & $\mathbf{2 0 1 3}$ & $\mathbf{2 0 1 4}$ & $\mathbf{2 0 1 5}$ & $\mathbf{2 0 1 6}$ & $\mathbf{2 0 1 7}$ & $\mathbf{2 0 1 8}$ \\
\hline Andalucía & $195.271,59$ & $195.271,59$ & $\mathbf{2 0 2 . 9 7 6 , 9 0}$ & $\mathbf{2 0 2 . 9 7 6 , 9 0}$ & $202.976,90$ & $202.976,90$ & $202.976,90$ & $202.976,90$ & $\mathbf{0 , 0 0}$ \\
\hline Aragón & $195.271,59$ & $195.271,59$ & $195.271,59$ & $\mathbf{1 3 0 . 8 3 1 , 9 7}$ & $\mathbf{9 7 . 6 3 5 , 7 9}$ & $\mathbf{6 8 . 3 4 5 , 0 6}$ & $68.345,06$ & $68.345,06$ & $68.345,06$ \\
\hline P. Asturias & $195.271,59$ & $\mathbf{2 0 0 . 9 3 3 , 4 8}$ & $200.933,48$ & $200.933,48$ & $200.933,48$ & $200.933,48$ & $200.933,48$ & $\mathbf{1 7 2 . 7 0 0 . 0 0}$ & $\mathbf{1 4 1 . 4 5 0 , 0 0}$ \\
\hline Baleares & $192.581,26$ & $192.581,26$ & $192.581,26$ & $192.581,26$ & $192.581,26$ & $192.581,26$ & $\mathbf{1 3 . 0 0 0 , 0 0}$ & $13.000,00$ & $13.000,00$ \\
\hline Canarias & $1.945,15$ & $1.945,15$ & $1.945,15$ & $\mathbf{1 9 3 . 1 3 9 , 0 7}$ & $193.139,07$ & $193.139,07$ & $\mathbf{1 9 3 , 1 4}$ & 193,14 & 193,14 \\
\hline Cantabria & $9.257,19$ & $9.257,19$ & $\mathbf{1 . 8 5 1 , 4 4}$ & $1.851,44$ & $1.851,44$ & $1.851,44$ & $1.851,44$ & $1.851,44$ & $\mathbf{1 8 . 5 1 4 , 3 8}$ \\
\hline C. León & $1.821,69$ & $1.821,69$ & $1.821,69$ & $\mathbf{1 7 0 . 5 5 3 , 4 3}$ & $170.553,43$ & $170.553,43$ & $\mathbf{1 4 8 . 2 4 0 , 9 3}$ & $148.240,93$ & $\mathbf{1 0 3 . 6 1 5 , 9 3}$ \\
\hline C.-La Mancha & $9.763,58$ & $9.763,58$ & $9.763,58$ & $9.763,58$ & $9.763,58$ & $9.763,58$ & $9.763,58$ & $\mathbf{3 9 . 0 5 4 , 3 2}$ & $39.054,32$ \\
\hline Cataluña & $87.000,00$ & $87.000,00$ & $\mathbf{8 7 0 , 0 0}$ & 870,00 & $\mathbf{9 . 7 2 0 , 0 0}$ & $9.720,00$ & $9.720,00$ & $9.720,00$ & $9.720,00$ \\
\hline Extremadura & $195.271,59$ & $195.271,59$ & $195.271,59$ & $195.271,59$ & $195.271,59$ & $195.271,59$ & $195.271,59$ & $195.271,59$ & $\mathbf{2 . 4 0 2 , 7 2}$ \\
\hline
\end{tabular}

3 Para un análisis detallado de la incidencia económica del ITPAJD desde la perspectiva del sujeto activo (CC.AA), es decir, su incidencia presupuestaria en el periodo 2006-2016, véase: ORTEGA, VÍLCHEZ Y ROJO (2020). 
GAPP. Nueva Época - N. 24, noviembre 2020 - ISSN: 1989-8991 - DOI: https://doi.org/10.24965/gapp.i24.10744 - [Págs. 63-85]

Impuestos sobre la riqueza y el ciclo político en el ámbito autonómico M. ${ }^{a}$ Ángeles Ortega Almón / Inmaculada Moreno Foronda / Araceli Rojo Gallego-Burin

\begin{tabular}{lrrrrrrrrr}
\hline CC.AA/AÑOS & $\mathbf{2 0 1 0}$ & \multicolumn{1}{c}{$\mathbf{2 0 1 1}$} & $\mathbf{2 0 1 2}$ & $\mathbf{2 0 1 3}$ & $\mathbf{2 0 1 4}$ & $\mathbf{2 0 1 5}$ & $\mathbf{2 0 1 6}$ & $\mathbf{2 0 1 7}$ & $\mathbf{2 0 1 8}$ \\
\hline Galicia & $76.520,00$ & $76.520,00$ & $76.520,00$ & $76.520,00$ & $76.520,00$ & $76.520,00$ & $\mathbf{3 4 . 5 0 0 , 0 0}$ & $34.500,00$ & $34.500,00$ \\
\hline Madrid & $1.952,59$ & $1.952,59$ & $1.952,59$ & $1.952,59$ & $1.952,59$ & $1.952,59$ & $1.951,96$ & $1.951,96$ & $1.951,96$ \\
\hline R. Murcia & $195.271,59$ & $195.271,59$ & $195.271,59$ & $\mathbf{2 0 2 . 9 7 7 , 0 5}$ & $202.977,05$ & $202.977,05$ & $\mathbf{1 0 1 . 4 8 8 , 5 2}$ & $\mathbf{8 1 . 1 9 0 , 8 2}$ & $\mathbf{2 0 . 2 9 7 , 7 1}$ \\
\hline La Rioja & $1.952,72$ & $1.952,72$ & $1.952,72$ & $1.952,72$ & $1.952,72$ & $1.952,72$ & $\mathbf{3 . 9 0 5 , 4 3}$ & $3.905,43$ & $3.905,43$ \\
\hline C. Valenciana & $1.881,19$ & $1.881,19$ & $1.881,19$ & $1.888,63$ & $\mathbf{4 2 . 7 5 3 , 1 3}$ & $42.753,13$ & $42.753,13$ & $\mathbf{8 5 . 5 0 6 , 2 6}$ & $85.506,26$ \\
\hline
\end{tabular}

Notas:

- El sombreado azul indica que ese año se celebraron elecciones autonómicas en dicha Comunidad.

- El color rojo representa una subida de la deuda tributaria respecto al año anterior para un mismo hecho imponible, mientras que el color verde indica una reducción.

Fuente: Elaboración Propia.

Desde el primer año del periodo que se analiza, se pueden observar las grandes diferencias que existen a la hora de liquidar el Impuesto de Sucesiones y Donaciones según la Comunidad en la que haya residido el fallecido en los últimos cinco años. En el año 2010, las cuantías de la deuda tributaria a pagar por el sujeto pasivo oscilan entre dos importes prácticamente extremos, como son desde 1.821,69€ hasta 195.271,59€. En este año solo hay cinco CC.AA (Canarias, Castilla y León, Comunidad de Madrid, La Rioja y la Comunidad Valenciana) que resultan atractivas para los contribuyentes en relación a la liquidación del Impuesto, ya que estas Comunidades no sobrepasan los $2.000 €$ de cuota tributaria. Siendo las Comunidades más perjudiciales para hacer frente al pago Andalucía, Aragón, el Principado de Asturias, Baleares, Extremadura y Murcia.

A medida que avanza el tiempo en el periodo que se analiza, estas cuantías van cambiando, tanto incrementándose como disminuyéndose, llegando así al último año, 2018, con unas cantidades muy variadas. Esta vez la cantidad máxima a pagar de deuda tributaria serían $141.450,00 €$ en el Principado de Asturias, siendo la mínima $0,00 €$ en Andalucía. Nuevamente, entre estas dos cantidades son reflejo de situaciones extremas. Cabe destacar que en 2018 la mayoría de las CC.AA reducen la cuantía, a pagar por los sujetos pasivos en la liquidación de este Impuesto, con respecto a los años anteriores analizados. En dicho año, las Comunidades más atractivas fiscalmente para los sujetos pasivos son: Andalucía, Canarias, Comunidad de Madrid e, incluso, Extremadura, ya que son las que no excede la deuda tributaria de $2.400 €$. Sin embargo, los sujetos pasivos que se verían más perjudicados serían los que dispongan de su domicilio fiscal en el Principado de Asturias, Castilla y León y la Comunidad Valenciana, de las cuales dos de ellas en el año 2010 resultaban tener de las cuantías más reducidas para los sujetos.

De los impuestos analizados que gravan la riqueza, el que presenta mayores desigualdades territoriales y cambios más bruscos, como se ha observado anteriormente, con respecto a su liquidación es el Impuesto sobre Sucesiones y Donaciones. Estas disparidades se deben a las modificaciones continuas que las CC.AA aprueban en las tarifas propias, reducciones y bonificaciones (véase tabla 6 a modo de ejemplo). Es preciso recordar que el grado de parentesco, el grado de discapacidad y el patrimonio preexistente del contribuyente antes de recibir la herencia, conlleva reducciones y bonificaciones totalmente distintas, según la Comunidad.

TAbla 6. Porcentaje de bonificaciones ${ }^{4}$ en la Cuota del ISD aplicable a Cada CC.AA de RÉgimen Común (2010-2018)

\begin{tabular}{lrrrrrrrrr}
\hline CC.AA/AÑOS & $\mathbf{2 0 1 0}$ & \multicolumn{1}{c}{$\mathbf{2 0 1 1}$} & $\mathbf{2 0 1 2}$ & $\mathbf{2 0 1 3}$ & $\mathbf{2 0 1 4}$ & $\mathbf{2 0 1 5}$ & $\mathbf{2 0 1 6}$ & $\mathbf{2 0 1 7}$ & $\mathbf{2 0 1 8}$ \\
\hline Andalucía & $0 \%$ & $0 \%$ & $0 \%$ & $0 \%$ & $0 \%$ & $0 \%$ & $0 \%$ & $0 \%$ & $\mathbf{1 0 0 \%}$ \\
\hline Aragón & $0 \%$ & $0 \%$ & $0 \%$ & $\mathbf{3 3} \%$ & $\mathbf{5 0 \%}$ & $\mathbf{6 5 \%}$ & $\mathbf{6 5 \%}$ & $\mathbf{6 5 \%}$ & $65 \%$ \\
\hline Canarias & $99 \%$ & $99 \%$ & $99 \%$ & $\mathbf{0} \%$ & $0 \%$ & $0 \%$ & $\mathbf{9 9 , 9} \%$ & $99,9 \%$ & $99,9 \%$ \\
\hline Cantabria & $95 \%$ & $95 \%$ & $\mathbf{9 9} \%$ & $99 \%$ & $99 \%$ & $99 \%$ & $99 \%$ & $99 \%$ & $90 \%$ \\
\hline
\end{tabular}

4 Las CC.AA que no figuran en la siguiente tabla son las que no han aplicado ningún tipo de bonificación a lo largo del periodo analizado. 
GAPP. Nueva Época - N. 24, noviembre 2020 - ISSN: 1989-8991 - DOI: https://doi.org/10.24965/gapp.i24.10744 - [Págs. 63-85]

Impuestos sobre la riqueza y el ciclo político en el ámbito autonómico M. ${ }^{a}$ Ángeles Ortega Almón / Inmaculada Moreno Foronda / Araceli Rojo Gallego-Burin

\begin{tabular}{lrrrrrrrrr}
\hline CC.AA/AÑOS & $\mathbf{2 0 1 0}$ & $\mathbf{2 0 1 1}$ & $\mathbf{2 0 1 2}$ & $\mathbf{2 0 1 3}$ & $\mathbf{2 0 1 4}$ & $\mathbf{2 0 1 5}$ & $\mathbf{2 0 1 6}$ & $\mathbf{2 0 1 7}$ & $\mathbf{2 0 1 8}$ \\
\hline C. León & $99 \%$ & $99 \%$ & $99 \%$ & $\mathbf{0} \%$ & $0 \%$ & $0 \%$ & $0 \%$ & $0 \%$ & $0 \%$ \\
\hline C.-La Mancha & $95 \%$ & $95 \%$ & $95 \%$ & $95 \%$ & $95 \%$ & $95 \%$ & $95 \%$ & $\mathbf{8 0} \%$ & $80 \%$ \\
\hline Cataluña & $0 \%$ & $0 \%$ & $\mathbf{9 9} \%$ & $99 \%$ & $\mathbf{8 8} \%$ & $88 \%$ & $88 \%$ & $88 \%$ & $88 \%$ \\
\hline Extremadura & $0 \%$ & $0 \%$ & $0 \%$ & $0 \%$ & $0 \%$ & $0 \%$ & $0 \%$ & $0 \%$ & $\mathbf{9 9} \%$ \\
\hline Madrid & $99 \%$ & $99 \%$ & $99 \%$ & $99 \%$ & $99 \%$ & $99 \%$ & $99 \%$ & $99 \%$ & $99 \%$ \\
\hline R. Murcia & $0 \%$ & $0 \%$ & $0 \%$ & $0 \%$ & $0 \%$ & $0 \%$ & $\mathbf{5 0} \%$ & $\mathbf{6 0} \%$ & $\mathbf{9 0} \%$ \\
\hline La Rioja & $99 \%$ & $99 \%$ & $99 \%$ & $99 \%$ & $99 \%$ & $99 \%$ & $\mathbf{9 8} \%$ & $98 \%$ & $98 \%$ \\
\hline C. Valenciana & $99 \%$ & $99 \%$ & $99 \%$ & $99 \%$ & $\mathbf{7 5 \%}$ & $75 \%$ & $\mathbf{7 5} \%$ & $\mathbf{5 0 \%}$ & $50 \%$ \\
\hline
\end{tabular}

Notas:

- El sombreado azul indica que ese año se celebraron elecciones autonómicas en dicha Comunidad.

- El color rojo representa una subida de la deuda tributaria respecto al año anterior para un mismo hecho imponible, mientras que el color verde indica una reducción.

Fuente: Elaboración propia.

Se pueden comprobar variaciones extremas que se producen en algunas CC.AA, pasando de no establecer ninguna bonificación, implicando una deuda tributaria muy elevada a aplicar un $99 \%$ o $100 \%$ de bonificación y reducir en un solo año inmensamente la cantidad a pagar por el contribuyente, o viceversa. Ejemplo de ello, es Andalucía, donde por la misma herencia, un contribuyente pagaría 202.976,90€ de 2012 a 2017, mientras en 2018, no pagaría nada. Como se observa, en el año 2010, coexisten Comunidades que no aplicaban ningún tipo de bonificación para determinar la deuda tributaria del Impuesto, mientras que otras sí lo hacían aplicando altos porcentajes de la misma, superiores al $90 \%$, hecho que provoca que el pago de la cuantía sea mucho menor. No obstante, en el año 2018, se observa que el número de CC.AA que establecen bonificaciones aumenta de manera considerable, aunque esta vez son porcentajes más variados (entre el $50 \%$ y el $100 \%$ ). En general, las cantidades a ingresar por la liquidación del Impuesto, en 2018, son más favorables para los sujetos pasivos que al principio del periodo analizado. En el apartado siguiente se tratará de contrastar si dicho comportamiento está relacionado con los periodos pre-electorales y post-electorales.

\section{CICLO POLÍTICO Y DEUDA TRIBUTARIA DE LOS IMPUESTOS SOBRE LA RIQUEZA CEDIDOS A LAS COMUNIDADES AUTÓNOMAS DE RÉGIMEN COMÚN}

Como se ha puesto de manifiesto en los apartados anteriores, existen diferencias muy apreciables a la hora de hacer frente a la liquidación de los Impuestos sobre la Riqueza cedidos a las CC.AA, en función de la Comunidad en la que un sujeto pasivo tenga su domicilio fiscal. Estas desigualdades provocan diferencias en la renta disponible de los contribuyentes, afectando a los niveles de consumo, ahorro e inversión, y creando disparidades territoriales. La fuerte crisis económica de los últimos años y consiguiente caída de la recaudación, unido a la necesidad de cumplir el objetivo de déficit ha llevado, a algunas Comunidades, a recuperar o incrementar los impuestos cedidos por el Estado, en los que tienen competencias normativas, muy unidos estos cambios, en ambos casos, al ciclo político. Es decir, al uso de forma electoralista de las formas tributarias que gravan la riqueza.

A continuación, se pretende comprobar, en el periodo analizado, si los cambios electorales ${ }^{5}$ que se han producido en las distintas CC.AA de régimen común han influido en las variaciones de los tipos impositivos, reducciones, deducciones o bonificaciones y, por tanto, han ocasionado cambios significativos en las cuotas tributarias a pagar por los contribuyentes en dichos impuestos que gravan las distintas manifestaciones de la riqueza.

5 La información sobre los cambios electorales, así como de los distintos partidos políticos y los escaños que se han obtenido en cada Parlamento autonómico proceden de la página web de la Junta Electoral Central y de las páginas oficiales de cada CC.AA de régimen común. Véase a este respecto el Anexo I. 
En las figuras 1 , y 3 se sintetizan y comparan las deudas tributarias de los tres impuestos sobre la riqueza cedidos a las CC.AA recogidas en las tablas 2, 4 y 5 de este trabajo, pero sólo para los años en los que se han celebrado mayoritariamente elecciones autonómicas (con las salvedades de algunas Comunidades que posteriormente se detallará $)^{6}$ que son 2011 y 2015 . Asimismo, se reflejan las deudas tributarias correspondientes al año 2018, previo a las elecciones autonómicas de 2019.

En el caso de Andalucía, el PSOE gana las elecciones en marzo de 2012 pactando con IU. Ese mismo año, y como consecuencia del pacto acuerdan una subida post-electoral del tipo impositivo del impuesto sobre transmisiones al $8 \%$, y una subida del Impuesto sobre el Patrimonio en 2013. Ambos impuestos, se han mantenido sin cambios pues dicho partido ha seguido gobernando hasta 2018, aunque con diferentes socios de gobierno y de distinto signo político (con CIUDADANOS, desde 2015). Si se produce un cambio espectacular en la liquidación del Impuesto sobre Sucesiones, en 2018, al aprobarse la aplicación de una bonificación del $100 \%$ de la cuota tributaria para el supuesto que se ha analizado anteriormente. Pasa de ser la Comunidad con la deuda tributaria más elevada de dicho impuesto en todos los años analizados, hasta que en 2018 es la más generosa, en concreto, cero euros (véase figura 3). Ello puede deberse a que éste, es un año preelectoral, la presión de Ciudadanos, socio de gobierno y la inestabilidad presupuestaria, pudiendo ser una medida de marketing político para la obtención de votos en las siguientes elecciones autonómicas, adelantándose su celebración, finalmente, al 2 de diciembre de 2018.

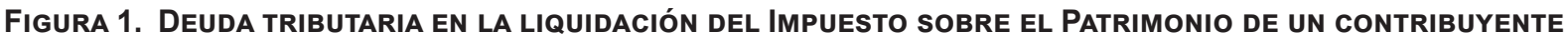 CON UN PATRIMONIO NETO DE 4 MILLONES DE EUROS $(2012,2015$ Y 2018)}

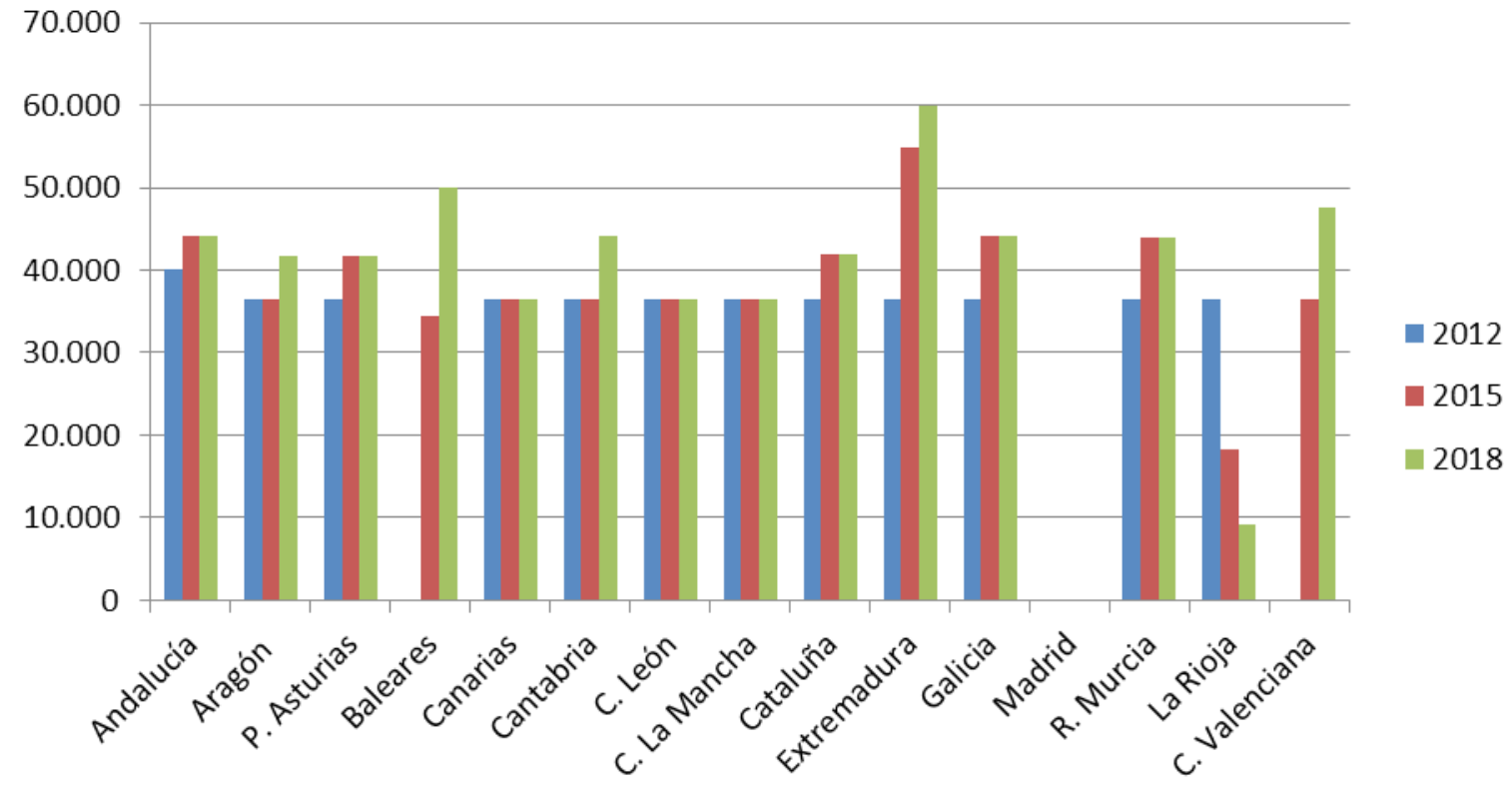

Fuente: Elaboración propia.

En el Principado de Asturias, Foro Asturias Ciudadanos llega al gobierno en 2011 y suben tanto el Impuesto sobre el Patrimonio, como el tipo de gravamen al $8 \%$ del Impuesto sobre Transmisiones y, ligeramente, Sucesiones y Donaciones, previendo una legislatura completa. Sin embargo, dura solo unos meses, ya que el PSOE toma el relevo en el gobierno a partir de 2012, pactando con IU (Izquierda Unida) y UPyD (Unión Progreso y Democracia), manteniendo el mismo tipo impositivo durante la legislatura, hasta el último año analizado tras las elecciones de 2015. Ello hace intuir que la ligera subida de impuestos en 2011 fue una medida de reducir el déficit consecuencia de la crisis económica.

6 Recuérdese, que en todas las tablas presentadas en el trabajo, se ha sombreado en azul el año en el que cada Comunidad Autónoma de régimen común ha celebrado elecciones desde el año 2010, siendo Cataluña, la única que celebró elecciones autonómicas, en dicho año. 
FIGURA 2. DEUdA TRIBUTARIA EN LA LIQUIDACIÓN DEL ITPYAJD (MODALIDAD TRANSMISIONES PATRIMONIALES DE INMUEBLES) DE UN CONTRIBUYENTE DE 38 AÑOS DE EDAD QUE ADQUIERE SU VIVIENDA HABITUAL POR VALOR DE 120.000 EUROS $(2011,2015$ Y 2018)

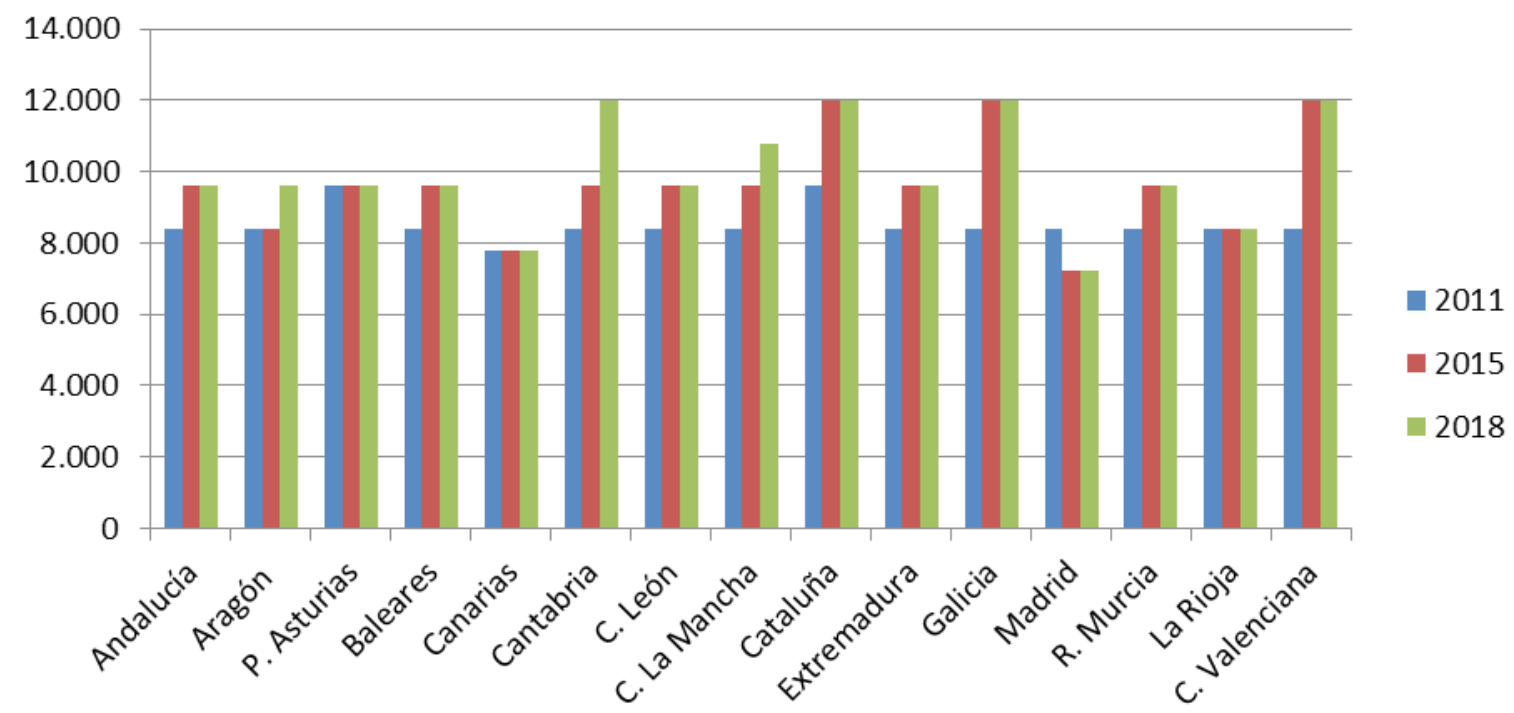

Fuente: Elaboración propia.

FiguRA 3. DEUdA TRIBUTARIA A PAGAR POR UN CONTRIBUYENTE (GRADO DE PARENTESCO 2) QUE RECIBE UNA MASA HEREDITARIA NETA DE $\mathbf{8 0 0 . 0 0 0}$ EUROS Y CON UN PATRIMONIO PREEXISTENTE DE $\mathbf{3 0 0 . 0 0 0}$ EUROS EN LA MODALIDAD DE SUCESIONES (MORTIS CAUSA) DEL ISD $(2011,2015$ Y 2018)

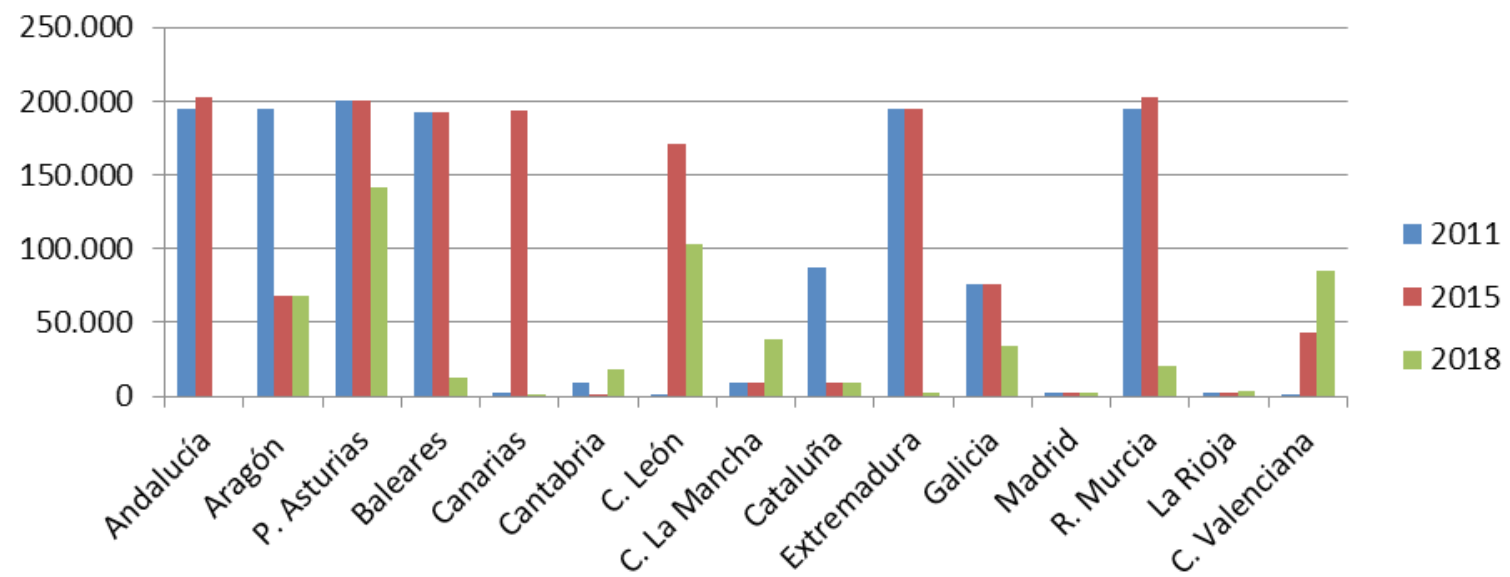

Fuente: Elaboración propia.

En las Islas Canarias, el partido Coalición Canaria permanece en el gobierno todos los años analizados, mediante pactos con el PSOE y diferentes partidos. Es en esta Comunidad donde se mantiene estable la deuda tributaria tanto del IP, como el de Transmisiones patrimoniales, con el segundo tipo más reducido de todas las CC.AA (6,5\%), detrás de Madrid (6\%). Sin embargo, entre 2013 y 2015, se produce un aumento considerable de la deuda tributaria del Impuesto sobre Sucesiones, que obedece, más a un intento de reducir el déficit presupuestario en los años de crisis, ya que tras las elecciones de 2015, y continuando Coalición Canaria en el gobierno, se lleva a cabo una reducción muy importante de la deuda tributaria del ISD.

En Cataluña CiU (Convergencia y Unión) gana las elecciones con mayoría simple en 2010 y ya en periodo post-electoral (2011) sube solo el Impuesto sobre Transmisiones. Obligada a convocar elecciones, 
por la inestabilidad política, en noviembre de 2012, revalida su gobierno pero en coalición con ERC (Esquerra Republicana de Cataluña), de cuyo pacto proviene la iniciativa de subir considerablemente el Impuesto sobre el Patrimonio en 2013 y el de Transmisiones en 2014 a un $10 \%$. Se convocan elecciones en 2015 en las que toma el relevo J x Sí (Junts per Sí) pactando con la CUP (Candidatura d'Unitat Popular-Alternativa d'Esquerres) y aunque mantiene sin cambios la deuda tributaria del IP y de Transmisiones, dada la dificultosa situación política que atraviesan en los siguientes años. Sin embargo, en el Impuesto sobre Sucesiones tiene lugar un aumento importante de la deuda tributaria a partir de 2014, pero muy inferior a la cuantía correspondiente al año electoral de 2010 (véase figura 3).

Las Comunidades de I. Baleares, C. León, Extremadura y Murcia, con gobiernos del PP desde 2011, suben el impuesto sobre transmisiones del $7 \%$ al $8 \%$, dos años después de su entrada en el gobierno (en 2013). Lo mismo ocurre con el Impuesto sobre el Patrimonio, manteniendo una deuda tributaria elevada en el Impuesto sobre Sucesiones. Sin embargo, respecto a éste último, se produce un cambio muy significativo a partir del cambio del signo político en la composición de los parlamentos autonómicos tras las elecciones de 2015. En Baleares comienzan a gobernar en coalición PSOE, Podemos, Més y GxF, produciéndose una subida muy importante de la deuda tributaria del IP, al mismo tiempo que una reducción espectacular del ISD (véanse figuras 1 y 3 , respectivamente). El mismo comportamiento se observa en Extremadura, respecto al IP, que tras las elecciones de 2015, pactan gobierno PSOE y Podemos. Sin embargo, el ISD sigue siendo de los más altos de todas las Comunidades hasta 2018, que se aprueba una bonificación del $99 \%$ en los grados de parentesco I y II (véase tabla 6 y figura 3). Similar comportamiento presenta la Comunidad de Murcia que siendo de los más elevados también se aprueba a partir de 2016 bonificaciones crecientes hasta alcanzar en 2018 , una bonificación del $90 \%$ de la cuota, reduciéndose considerablemente la deuda tributaria del contribuyente.

Galicia gobernada por el PP con mayoría absoluta, al igual que las anteriores Comunidades sube su Impuesto sobre Transmisiones de Inmuebles al 10\% en el mismo año, manteniéndolo también hasta la actualidad. Lo mismo ocurre con el IP. Estas subidas tras las elecciones autonómicas celebradas en dicha Comunidad en 2012, se debieron tomar por la urgente necesidad de incrementar la recaudación que hasta ese momento había sido muy baja causada por la crisis y el estallido de la burbuja inmobiliaria. El Impuesto sobre Sucesiones y Donaciones si reducen casi un $50 \%$ la deuda tributaria para un mismo sujeto pasivo justo en el año de las elecciones celebradas en dicha Comunidad de 2016 (y no en 2015, como en la mayoría de las CC.AA) que se mantiene hasta la actualidad.

En 2011 en Aragón gobierna el PP mediante pacto con el PAR (Partido Aragonesista). Estos deciden mantener un tipo impositivo bajo del impuesto sobre Transmisiones del $7 \%$ hasta que en las elecciones de 2015 se produce un cambio de gobierno donde el PSOE pacta con PODEMOS, CHA (Chunta Aragonesista) e IU y es en el periodo post-electoral (año 2016) cuando suben el impuesto al $8 \%$, manteniéndolo hasta la actualidad. Asimismo, en la misma línea, se lleva a cabo una subida importante del IP. Sin embargo, llama la atención que a partir de 2014, año pre-electoral se reduce la deuda tributaria del ISD como consecuencia de la aprobación de bonificaciones en la cuota que van del $50 \%$ en 2014 al $65 \%$ en 2018 (véase tabla 6 y figura 3 ).

En las Comunidades de Cantabria y Castilla la Mancha el PP, después de dos años de gobierno, en 2013, sube el ITP de inmuebles al $8 \%$. En las elecciones de 2015, en Castilla la Mancha gobierna el PSOE por pacto con PODEMOS y en ese mismo año, en Cantabria gobierna el PRC (Partido Regionalista de Cantabria) por pacto con el PSOE. En ambos casos van a realizar una subida del tipo impositivo al $9 \%$ y al $10 \%$, en los años 2017 y 2018 respectivamente. En el caso de Cantabria, en 2019 lo bajará al $9 \%$, coincidiendo con un año electoral y probablemente como medida preelectoral. Sin embargo, en ambas Comunidades se mantiene estable el IP, excepto en Cantabria que aumenta la deuda tributaria casi 10.000 euros en 2018 . Al igual que la cuota tributaria del ISD al reducirse del $99 \%$ al $90 \%$ las bonificaciones de la cuota en los grados de parentesco I y II (véase tabla 6 y figura 3). En Castilla-La Mancha en 2017 y 2018 aumenta considerablemente la deuda tributaria de Sucesiones y Donaciones.

Es de destacar que Comunidades como Madrid y La Rioja gobernadas por el PP con mayorías absolutas o mediante pactos con CIUDADANOS hayan mantenido tipos impositivos bajos en ITP de inmuebles (6\% y $7 \%$ ) e incluso llegando a rebajarlo al $6 \%$ en el 2014, en el caso de la Comunidad de Madrid, coincidiendo con la cercanía de las elecciones de 2015. El IP mantiene hasta la actualidad una bonificación del $100 \%$ así como el ISD una bonificación del $99 \%$. Por tanto, es la Comunidad con los impuestos sobre la riqueza más bajos. La Rioja a partir de las elecciones de 2015 reduce considerablemente el IP pero sube ligeramente el ISD al reducir las bonificaciones de la cuota del $99 \%$ al $98 \%$. 
En la Comunidad Valenciana el PP, dos años después de estar en el gobierno con mayoría absoluta, sube el ITP de inmuebles de forma sucesiva en los años 2013 y 2014 hasta llevarlo al $10 \%$, el cual será mantenido, a partir del resultado de las elecciones de 2015, por el gobierno del PSOE, PODEMOS y COMPROMIS desde 2015 en adelante. En 2013, también sube el IP, al eliminarse la bonificación existente del $100 \%$. La subida de ambos impuestos coincide con los años más duros de la crisis económica y el aumento de los déficits y de la deuda pública autonómica. Tras las elecciones de 2011 mantiene el ISD hasta un año antes de las elecciones de 2015 que aumenta considerablemente la deuda tributaria, duplicándose, prácticamente, a partir de los resultados electorales de 2015 y con el cambio de signo político en la composición del parlamento autonómico. A partir del resultado de dichas elecciones, tiene lugar una subida muy importante, también del IP.

\section{CONCLUSIONES}

Los impuestos que gravan la riqueza son un instrumento fundamental en todo país desarrollado, que pretenda fundamentar su política fiscal sobre la base de la equidad y el derecho a la igualdad de oportunidades de todos sus ciudadanos. Contribuyen a lograr una mejor redistribución de la riqueza, reduciendo la concentración y la perpetuación de ésta, incentivando una utilización más productiva de los activos (reales y financieros). Asimismo, proporcionan una importante información fiscal que permite un mayor control recaudatorio, procurando una disminución del fraude fiscal. Por el contrario, estos impuestos tienen un efecto negativo sobre el ahorro y la inversión, lo que puede afectar negativamente al crecimiento económico.

En el caso de España, el hecho de que las Comunidades Autónomas de régimen común tengan competencias normativas sobre tres de estos impuestos, permitiéndoles aplicar deducciones, exenciones, bonificaciones o modificar los tipos impositivos legales, siendo éstos los elementos determinantes claves del tipo impositivo real ${ }^{7}$ y por tanto, de la deuda tributaria del sujeto pasivo, está provocando una desigualdad manifiesta, a la hora de tributar según la Comunidad. Dichos impuestos son: el Impuesto sobre el Patrimonio (IP), el Impuesto de Sucesiones y Donaciones (ISD) y el Impuesto de Transmisiones Patrimoniales y Actos Jurídicos Documentados (ITPAJD).

A lo largo del trabajo, se ha puesto de manifiesto, como la cesión de estas figuras tributarias a las Comunidades, está ocasionando que, por un mismo hecho imponible, un contribuyente, según su domicilio fiscal, tenga que afrontar una deuda tributaria diferente. Por tanto, generan un impacto diferente en la renta disponible de los contribuyentes, incidiendo de forma desigual sobre los niveles de consumo, ahorro e inversión de los ciudadanos. Asimismo, se ha podido constatar, que las subidas o bajadas de la deuda tributaria del sujeto pasivo, a lo largo del periodo analizado (2010-2018), están significativamente relacionadas con los cambios provocados por los ciclos políticos y por los periodos pre o post-electorales, según la configuración política del Parlamento de cada Comunidad. En general, se aprecia que cuando la tendencia política del partido gobernante es de signo liberal o conservador, la deuda tributaria que tiene que afrontar el contribuyente, en cada uno de los tres impuestos analizados, es considerablemente más baja en relación a la que hipotéticamente tendría que pagar en otras Comunidades con gobiernos que se definen como de centroizquierda o de izquierda del espectro político. Los contribuyentes más beneficiados fiscalmente, en todos los años analizados, son los de la Comunidad de Madrid, donde, desde las elecciones de 2011, gobierna el PP con mayoría absoluta y tras las elecciones de 2015, mediante pacto con Ciudadanos. Por el contrario, en general, han tenido que asumir una mayor deuda tributaria, los contribuyentes de Andalucía (excepto en el ISD a partir de 2018) y de Cataluña (excepto en el ISD tras las elecciones de 2012). A partir de los resultados electorales de 2015, aumenta considerablemente la deuda tributaria de los tres impuestos, en la Comunidad de Extremadura, donde se produce un cambio de signo político, gobernando el PSOE mediante pacto con Podemos; o en las Islas Baleares, con la coalición PSOE, Podemos, Més y GxF. Una subida muy pronunciada, de los tres impuestos que gravan la riqueza, se observa en la Comunidad Valenciana, tras la pérdida de la mayoría absoluta del PP, tras las elecciones de 2015, pasando a gobernar en coalición, PSOE, Compromís y Podemos.

7 Recuérdese que el tipo impositivo legal (Tle) se obtiene dividiendo la Cuota Íntegra entre la Base Liquidable: $\mathrm{TI}=(\mathrm{Cl} / \mathrm{BL}){ }^{*} 100$. La existencia de deducciones en la Cuota Íntegra o bonificaciones implica que disminuye la deuda tributaria del contribuyente y por tanto, el tipo impositivo que realmente paga. El tipo impositivo real se obtiene a partir de la Cuota Líquida (CL), siendo ésta: $\mathrm{CL}=\mathrm{Cl}-$ deducciones y bonificaciones. Por tanto, el tipo impositivo real (Tre) sería: (CL/BL)*100. 
No obstante, cabe mencionar que no es lo mismo que en una Comunidad gobierne un partido político con mayoría absoluta, a que gobierne en mayoría simple o mediante el apoyo de otros partidos. La mayoría de los cambios, que se han producido en los elementos principales de los distintos impuestos, han coincidido con los años electorales de las Comunidades o con los años post-electorales, cuando el nuevo gobierno comienza su legislatura. No obstante, se ha comprobado que tanto en los años pre-electorales como postelectorales, entorno a la celebración de elecciones autonómicas de 2011 (2010 en Cataluña y 2012 en Andalucía, Asturias, Galicia y repetición de elecciones en Cataluña), se produce una subida generalizada de los tres impuestos analizados, en todas las CC.AA, independientemente del signo político del parlamento de la Comunidad. Ello pone de manifiesto que las modificaciones al alza de éstos, obedecieron prioritariamente a las necesidades recaudatorias como consecuencia de la grave crisis económica por la que atravesó el país tras el «estallido de la burbuja inmobiliaria» y la crisis financiera de 2008. En estos años se produce un aumento exponencial del endeudamiento autonómico, unido a la obligación de cumplir con los objetivos de déficit público.

Sin embargo, el comportamiento es diferente en las elecciones autonómicas de 2015 (celebradas en Galicia, en 2016). En los años pre y post-electorales, se constata, en general, que en las Comunidades en las que han gobernado o gobiernan partidos, en lo que ellos mismos se definen como progresistas, como PSOE, Podemos, IU, FAC, CiU, ERC o Compromís, tienden a elevar los tipos impositivos o reducir las bonificaciones en la cuota de los tres impuestos analizados. Sin embargo, en las Comunidades en las que gobiernan partidos de signo conservador, como el PP, Ciudadanos o FAR tienden a disminuir muy significativamente la cuantía de deuda tributaria de los contribuyentes, sobre todo, en el ISD.

El impuesto en el que más se aprecia la disparidad territorial, en su liquidación, tras los resultados electorales de 2015, es en el ISD, generando éste desigualdades extremas, relacionadas con los años preelectorales y post-electorales. Ejemplo de ello, son Andalucía, Extremadura y Murcia. Son las Comunidades en las que el sujeto pasivo tiene que afrontar una mayor deuda tributaria por un mismo hecho imponible, en casi todo el periodo de tiempo analizado. Hasta antes de 2015, en el supuesto planteado en el trabajo, un mismo contribuyente afrontaba una deuda tributaria en torno a $200.000 €$ por una base liquidable de $800.000 €$, mientras que en Madrid, La Rioja o Cantabria sería de unos 1.900€. Sin embargo, desde 2016 hasta 2018, Murcia aprueba bonificaciones crecientes del impuesto por el pacto con Ciudadanos, reduciéndose considerablemente la deuda tributaria del contribuyente $(20.297,71 €)$. La diferencia es más acuciante en Andalucía. Tras las elecciones de 2015, el PSOE pacta con Ciudadanos y justo antes de las elecciones previstas para 2019, finalmente adelantadas en esta Comunidad a 2018, se aprueba, para este mismo año, una modificación extrema del impuesto, materializado, entre otros aspectos, en un aumento del mínimo exento de un millón de euros, pasando un mismo contribuyente de tener que pagar $202.979,90 €$, por un mismo hecho imponible hasta 31 de diciembre de 2017, a no pagar nada a partir del 1 de enero de 2018 (año finalmente electoral).

Con el objeto de intentar paliar, en lo posible, estas desigualdades y la posible competencia fiscal que se produce como consecuencia de ésta, sería recomendable acordar unos límites razonables, entre las CC.AA y el Estado, de los elementos principales que determinan la deuda tributaria. Como se señaló anteriormente, los contribuyentes de la Comunidad de Madrid son los que disfrutan de una fiscalidad sobre la riqueza más baja. Según datos de Gestha $(2017)^{8}$, de los 508 contribuyentes en España «súper-ricos» (patrimonio superior a 30 millones $€$ ), aproximadamente, la mitad (303) tienen su domicilio fiscal en Madrid. Asimismo, la mitad de los contribuyentes más acaudalados residen en Madrid (3.153 personas físicas). La posible pérdida de recaudación en la configuración de los impuestos sobre la riqueza, se ve compensada con creces, con el impacto que genera sobre la recaudación del IRPF, donde la Comunidad que lo recauda (está cedido el $50 \%$ a las CC.AA) es en la que tenga fijado, el sujeto pasivo, su domicilio fiscal. Esta desigualdad condiciona, por tanto, la recaudación de impuestos y los gastos destinados a redistribuir la renta y riqueza.

Es positivo que las CC.AA tengan capacidad para subir o bajar algunos impuestos, pero estableciéndose unos mínimos y máximos (horquilla) para todas las Comunidades, así cada una de ellas será corresponsable de su situación financiera, respetando de esta forma los objetivos marcados por Hacienda (controlando el déficit), así como rindiendo cuentas ante sus ciudadanos, por una mala gestión del gasto o por impuestos excesivos. El aumento de la deuda pública autonómica ha coexistido en numerosos casos con «políticas tributarias laxas».

8 Sindicato de Técnicos del Ministerio de Hacienda. Los cálculos de Gestha se han obtenido partir de la estadística de Patrimonio difundida por la Agencia Tributaria. 
GAPP. Nueva Época - N. ${ }^{\circ}$ 24, noviembre 2020 - ISSN: 1989-8991 - DOI: https://doi.org/10.24965/gapp.i24.10744 - [Págs. 63-85] Impuestos sobre la riqueza y el ciclo político en el ámbito autonómico M. ${ }^{a}$ Ángeles Ortega Almón / Inmaculada Moreno Foronda / Araceli Rojo Gallego-Burin

\section{ANEXO I: MAPA ELECTORAL Y CAMBIOS POLÍTICOS}

\begin{tabular}{|c|c|c|c|}
\hline \multirow{8}{*}{$\begin{array}{l}\text { Parlamento } \\
\text { de Andalucía }\end{array}$} & \multirow{3}{*}{ Año 2012} & PSOE: 47 escaños & \multirow{3}{*}{ Gobierna el PSOE mediante pacto con IU } \\
\hline & & PP: 50 escaños & \\
\hline & & IU: 12 escaños & \\
\hline & \multirow{5}{*}{ Año 2015* } & PSOE: 47 escaños & \multirow{5}{*}{$\begin{array}{l}\text { Gobierna el PSOE mediante pacto } \\
\text { con Ciudadanos }\end{array}$} \\
\hline & & PP: 33 escaños & \\
\hline & & Podemos: 15 escaños & \\
\hline & & Ciudadanos: 9 escaños & \\
\hline & & IU: 5 escaños & \\
\hline
\end{tabular}

* Se adelantaron las elecciones un año a petición de la Presidenta de la Junta de Andalucía debido a la desconfianza hacia IU y a la situación de «inestabilidad».

\begin{tabular}{|c|c|c|c|}
\hline \multirow{12}{*}{$\begin{array}{l}\text { Cortes } \\
\text { de Aragón }\end{array}$} & \multirow{5}{*}{ Año 2011} & PP: 30 escaños & \multirow{5}{*}{ Gobierna el PP mediante pacto con PAR } \\
\hline & & PSOE: 22 escaños & \\
\hline & & $\begin{array}{l}\text { PAR: } 7 \text { escaños } \\
\text { (Partido Aragonés) }\end{array}$ & \\
\hline & & $\begin{array}{l}\text { CHA: } 4 \text { escaños } \\
\text { (Chunta Aragonesista) }\end{array}$ & \\
\hline & & IU: 4 escaños & \\
\hline & \multirow{7}{*}{ Año 2015} & PP: 21 escaños & \multirow{7}{*}{$\begin{array}{l}\text { Gobierna el PSOE mediante pacto } \\
\text { con Podemos, CHA e IU }\end{array}$} \\
\hline & & PSOE: 18 escaños & \\
\hline & & Podemos: 14 escaños & \\
\hline & & PAR: 6 escaños & \\
\hline & & Ciudadanos: 5 escaños & \\
\hline & & CHA: 2 escaños & \\
\hline & & IU: 1 escaño & \\
\hline \multirow{9}{*}{$\begin{array}{l}\text { Junta General } \\
\text { del Principado } \\
\text { de Asturias }\end{array}$} & \multirow{4}{*}{ Año 2011} & $\begin{array}{l}\text { FAC: } 16 \text { escaños } \\
\text { (Foro Asturias Ciudadanos) }\end{array}$ & \multirow{4}{*}{ Gobierna FAC con mayoría simple } \\
\hline & & PSOE: 15 escaños & \\
\hline & & PP: 10 escaños & \\
\hline & & IU: 4 escaños & \\
\hline & \multirow{5}{*}{ Año 2012* } & PSOE: 17 escaños & \multirow{5}{*}{$\begin{array}{l}\text { Gobierna el PSOE mediante pacto con IU } \\
\text { y UPyD }\end{array}$} \\
\hline & & FAC: 12 escaños & \\
\hline & & PP: 7 escaños & \\
\hline & & IU: 5 escaños & \\
\hline & & $\begin{array}{l}\text { UPyD: } 1 \text { escaño } \\
\text { (Unión, Progreso y Democracia) }\end{array}$ & \\
\hline
\end{tabular}


GAPP. Nueva Época - N. 24, noviembre 2020 - ISSN: 1989-8991 - DOI: https://doi.org/10.24965/gapp.i24.10744 - [Págs. 63-85]

Impuestos sobre la riqueza y el ciclo político en el ámbito autonómico

M. ${ }^{a}$ Ángeles Ortega Almón / Inmaculada Moreno Foronda / Araceli Rojo Gallego-Burin

\begin{tabular}{|c|c|c|c|}
\hline \multirow{6}{*}{$\begin{array}{l}\text { Junta General } \\
\text { del Principado } \\
\text { de Asturias } \\
\text { (cont.) }\end{array}$} & \multirow{6}{*}{ Año 2015} & PSOE: 14 escaños & \multirow{6}{*}{ Gobierna el PSOE mediante pacto con IU } \\
\hline & & PP: 11 escaños & \\
\hline & & IU: 5 escaños & \\
\hline & & FAC: 3 escaños & \\
\hline & & Podemos: 9 escaños & \\
\hline & & Ciudadanos: 3 escaños & \\
\hline \multicolumn{4}{|c|}{$\begin{array}{l}\text { * Se comunica por parte del Presidente el adelantamiento de las elecciones } 3 \text { años, tras haber estado solo } 6 \\
\text { meses en el gobierno. El nuevo mandato durará hasta el } 2015 .\end{array}$} \\
\hline \multirow{14}{*}{$\begin{array}{l}\text { Parlamento de } \\
\text { Islas Baleares }\end{array}$} & \multirow{6}{*}{ Año 2011} & PP: 35 escaños & \multirow{6}{*}{ Gobierna el PP con mayoría absoluta } \\
\hline & & PSOE: 14 escaños & \\
\hline & & $\begin{array}{l}\text { PSM-IV-EXM: } 4 \text { escaños } \\
\text { (PSM-Iniciativa Verds-Entesa) }\end{array}$ & \\
\hline & & $\begin{array}{l}\text { PSOE-PACTE: } 4 \text { escaños } \\
\text { (PSOE-Pacte per Eivissa) }\end{array}$ & \\
\hline & & $\begin{array}{l}\text { PSM-EN: } 1 \text { escaño } \\
\text { (Partit Socialista de Menorca) }\end{array}$ & \\
\hline & & $\begin{array}{l}\text { GxF + PSOE: } 1 \text { escaño } \\
\text { (Gent per Formentera + PSOE) }\end{array}$ & \\
\hline & \multirow{8}{*}{ Año 2015} & PP: 20 escaños & \multirow{8}{*}{$\begin{array}{l}\text { Gobierna el PSOE junto a Podemos, } \\
\text { Més y GxF }\end{array}$} \\
\hline & & $\begin{array}{l}\text { PSIB-PSOE: } 14 \text { escaños } \\
\text { (Partido Socialista Islas } \\
\text { Baleares) }\end{array}$ & \\
\hline & & Podemos: 10 escaños & \\
\hline & & $\begin{array}{l}\text { Més: } 6 \text { escaños } \\
\text { (Més per Mallorca) }\end{array}$ & \\
\hline & & $\begin{array}{l}\text { EL PI: } 3 \text { escaños } \\
\text { (Proposta per les Illes) }\end{array}$ & \\
\hline & & $\begin{array}{l}\text { MpM: } 3 \text { escaños } \\
\text { (Més per Menorca) }\end{array}$ & \\
\hline & & Ciudadanos: 2 escaños & \\
\hline & & GxF + PSIB: 1 escaño & \\
\hline \multirow{4}{*}{$\begin{array}{l}\text { Parlamento } \\
\text { de Canarias }\end{array}$} & \multirow{4}{*}{ Año 2011} & PP: 21 escaños & \multirow{4}{*}{ Gobierna CC mediante pacto con el PSOE } \\
\hline & & $\begin{array}{l}\text { CC-PNC-CCN: } 21 \text { escaños } \\
\text { (Coalición Canaria-Partido } \\
\text { Nacionalista Canario) }\end{array}$ & \\
\hline & & PSOE: 15 escaños & \\
\hline & & Nueva Canarias: 3 escaños & \\
\hline
\end{tabular}


GAPP. Nueva Época - N. ${ }^{\circ}$ 24, noviembre 2020 - ISSN: 1989-8991 - DOI: https://doi.org/10.24965/gapp.i24.10744 - [Págs. 63-85] Impuestos sobre la riqueza y el ciclo político en el ámbito autonómico M. ${ }^{a}$ Ángeles Ortega Almón / Inmaculada Moreno Foronda / Araceli Rojo Gallego-Burin

\begin{tabular}{|c|c|c|c|}
\hline \multirow{6}{*}{$\begin{array}{l}\text { Parlamento de } \\
\text { Canarias (cont.) }\end{array}$} & \multirow{6}{*}{ Año 2015} & $\begin{array}{l}\text { CC-PNC-AHÍ: } 18 \text { escaños } \\
\text { (Coalición Canaria-Partido } \\
\text { Nacionalista Canario- } \\
\text { Agrupación Herreña } \\
\text { Independiente) }\end{array}$ & \multirow{6}{*}{ Gobierna CC junto a PNC, AHÍ, PSOE y ASG } \\
\hline & & PSOE: 15 escaños & \\
\hline & & PP: 12 escaños & \\
\hline & & Podemos: 7 escaños & \\
\hline & & Nueva Canarias: 5 escaños & \\
\hline & & $\begin{array}{l}\text { ASG: } 3 \text { escaños } \\
\text { (Agrupación Socialista Gomera) }\end{array}$ & \\
\hline \multirow{8}{*}{$\begin{array}{l}\text { Parlamento } \\
\text { de Cantabria }\end{array}$} & \multirow{3}{*}{ Año 2011} & PP: 20 escaños & \multirow{3}{*}{ Gobierna el PP con mayoría absoluta } \\
\hline & & $\begin{array}{l}\text { PRC: } 12 \text { escaños } \\
\text { (Partido Regionalista de } \\
\text { Cantabria) }\end{array}$ & \\
\hline & & PSOE: 7 escaños & \\
\hline & \multirow{5}{*}{ Año 2015} & PP: 13 escaños & \multirow{5}{*}{$\begin{array}{l}\text { Gobierna el PRC mediante pacto } \\
\text { con el PSOE }\end{array}$} \\
\hline & & PSOE: 5 escaños & \\
\hline & & Podemos: 3 escaños & \\
\hline & & Ciudadanos: 2 escaños & \\
\hline & & PRC: 12 escaños & \\
\hline \multirow{5}{*}{$\begin{array}{l}\text { Cortes } \\
\text { de Castilla- } \\
\text { La Mancha }\end{array}$} & \multirow{2}{*}{ Año 2011} & PP: 25 escaños & \multirow{2}{*}{ Gobierna el PP con mayoría absoluta } \\
\hline & & PSOE: 23 escaños & \\
\hline & \multirow{3}{*}{ Año 2015} & PP: 16 escaños & \multirow{3}{*}{$\begin{array}{l}\text { Gobierna el PSOE mediante pacto } \\
\text { con Podemos }\end{array}$} \\
\hline & & PSOE: 14 escaños & \\
\hline & & Podemos: 3 escaños & \\
\hline \multirow{10}{*}{$\begin{array}{l}\text { Cortes de } \\
\text { Castilla y León }\end{array}$} & \multirow{4}{*}{ Año 2011} & PP: 53 escaños & \multirow{4}{*}{ Gobierna el PP con mayoría absoluta } \\
\hline & & PSOE: 29 escaños & \\
\hline & & IU: 1 escaño & \\
\hline & & $\begin{array}{l}\text { UPL: } 1 \text { escaño } \\
\text { (Unión del Pueblo Leonés) }\end{array}$ & \\
\hline & \multirow{6}{*}{ Año 2015} & PP: 42 escaños & \multirow{6}{*}{ Gobierna el PP con mayoría simple } \\
\hline & & PSOE: 25 escaños & \\
\hline & & Podemos: 10 escaños & \\
\hline & & Ciudadanos: 5 escaños & \\
\hline & & IU: 1 escaño & \\
\hline & & UPL: 1 escaño & \\
\hline
\end{tabular}


GAPP. Nueva Época - N. ${ }^{\circ}$ 24, noviembre 2020 - ISSN: 1989-8991 - DOI: https://doi.org/10.24965/gapp.i24.10744 - [Págs. 63-85] Impuestos sobre la riqueza y el ciclo político en el ámbito autonómico M. ${ }^{a}$ Ángeles Ortega Almón / Inmaculada Moreno Foronda / Araceli Rojo Gallego-Burin

\begin{tabular}{|c|c|c|c|}
\hline \multirow{27}{*}{$\begin{array}{l}\text { Parlamento } \\
\text { de Cataluña }\end{array}$} & \multirow{7}{*}{ Año 2010} & $\begin{array}{l}\text { CiU: } 62 \text { escaños } \\
\text { (Convergencia y Unión) }\end{array}$ & \multirow{7}{*}{ Gobierna CiU con mayoría simple } \\
\hline & & $\begin{array}{l}\text { PSC: } 28 \text { escaños } \\
\text { (Partido Socialista de Cataluña) }\end{array}$ & \\
\hline & & PP: 18 escaños & \\
\hline & & $\begin{array}{l}\text { ICV-EUiA: } 10 \text { escaños } \\
\text { (Iniciativa per Catalunya Verds- } \\
\text { Esquerra Unida i Alternativa) }\end{array}$ & \\
\hline & & $\begin{array}{l}\text { ERC: } 10 \text { escaños } \\
\text { (Esquerra Republicana } \\
\text { de Cataluña) }\end{array}$ & \\
\hline & & $\begin{array}{l}\text { SI: } 4 \text { escaños } \\
\text { (Solidaritat catalana } \\
\text { per la Independencia) }\end{array}$ & \\
\hline & & Ciudadanos: 3 escaños & \\
\hline & \multirow{7}{*}{ Año 2012* } & CiU: 50 escaños & \multirow{7}{*}{ Gobierna CiU mediante pacto con ERC } \\
\hline & & ERC: 21 escaños & \\
\hline & & PSC: 20 escaños & \\
\hline & & PP: 19 escaños & \\
\hline & & ICV-EUiA: 13 escaños & \\
\hline & & Ciudadanos: 9 escaños & \\
\hline & & $\begin{array}{l}\text { CUP: } 3 \text { escaños } \\
\text { (Candidatura d'Unitat Popular- } \\
\text { Alternativa d'Esquerres) }\end{array}$ & \\
\hline & \multirow{6}{*}{ Año $2015^{* *}$} & $\begin{array}{l}\text { JxSí: } 62 \text { escaños } \\
\text { (Junts per sí) }\end{array}$ & \multirow{6}{*}{ Gobierna JxSí mediante pacto con CUP } \\
\hline & & Ciudadanos: 25 escaños & \\
\hline & & PSC: 16 escaños & \\
\hline & & $\begin{array}{l}\text { CatsíqueesPot: } 11 \text { escaños } \\
\text { (Catalunya sí que es Pot) }\end{array}$ & \\
\hline & & PP: 11 escaños & \\
\hline & & CUP: 10 escaños & \\
\hline & \multirow{7}{*}{ Año 2017} & Ciudadanos: 36 escaños & \\
\hline & & JUNTSxCAT: 34 escaños & \\
\hline & & ERC-Catsí: 32 escaños & \\
\hline & & PSC: 17 escaños & \\
\hline & & CatComú-Podem: 8 escaños & \\
\hline & & CUP: 4 escaños & \\
\hline & & PP: 4 escaños & \\
\hline \multicolumn{4}{|c|}{ * Anticipadas dos años. } \\
\hline ** Anticipa & eses. & & \\
\hline
\end{tabular}


GAPP. Nueva Época - N.2 24, noviembre 2020 - ISSN: 1989-8991 - DOI: https://doi.org/10.24965/gapp.i24.10744 - [Págs. 63-85] Impuestos sobre la riqueza y el ciclo político en el ámbito autonómico M. ${ }^{a}$ Ángeles Ortega Almón / Inmaculada Moreno Foronda / Araceli Rojo Gallego-Burin

\begin{tabular}{|c|c|c|c|}
\hline \multirow{7}{*}{$\begin{array}{l}\text { Asamblea } \\
\text { de Extremadura }\end{array}$} & \multirow{3}{*}{ Año 2011} & PP: 32 escaños & \multirow{3}{*}{ Gobierna el PP con mayoría simple } \\
\hline & & PSOE: 30 escaños & \\
\hline & & IU: 3 escaños & \\
\hline & \multirow{4}{*}{ Año 2015} & PSOE: 30 escaños & \multirow{4}{*}{$\begin{array}{l}\text { Gobierna el PSOE mediante pacto } \\
\text { con Podemos }\end{array}$} \\
\hline & & PP: 28 escaños & \\
\hline & & Podemos: 6 escaños & \\
\hline & & Ciudadanos: 1 escaño & \\
\hline \multirow{8}{*}{$\begin{array}{l}\text { Parlamento } \\
\text { de Galicia }\end{array}$} & \multirow{4}{*}{ Año $2012^{*}$} & PP: 41 escaños & \multirow{4}{*}{ Gobierna el PP con mayoría absoluta } \\
\hline & & $\begin{array}{l}\text { PSdeG: } 18 \text { escaños } \\
\text { (Partido Socialista de Galicia) }\end{array}$ & \\
\hline & & $\begin{array}{l}\text { AGE: } 9 \text { escaños } \\
\text { (Alternativa Galega de } \\
\text { Esquerda) }\end{array}$ & \\
\hline & & $\begin{array}{l}\text { BNG: } 7 \text { escaños } \\
\text { (Bloque Nacionalista Galego) }\end{array}$ & \\
\hline & \multirow{4}{*}{ Año 2016} & PP: 41 escaños & \multirow{4}{*}{ Gobierna el PP con mayoría absoluta } \\
\hline & & En Marea: 14 escaños & \\
\hline & & PSdeG: 14 escaños & \\
\hline & & BNG-NÓS: 6 escaños & \\
\hline
\end{tabular}

* Se adelantaron 6 meses por el presidente del Parlamento para hacerlas coincidir con el adelanto electoral del País Vasco.

\begin{tabular}{|c|c|c|c|}
\hline \multirow{8}{*}{$\begin{array}{l}\text { Asamblea } \\
\text { de la } \\
\text { Comunidad } \\
\text { de Madrid }\end{array}$} & \multirow{4}{*}{ Año 2011} & PP: 72 escaños & \multirow{4}{*}{ Gobierna el PP con mayoría absoluta } \\
\hline & & PSOE: 36 escaños & \\
\hline & & IU: 13 escaños & \\
\hline & & UPyD: 8 escaños & \\
\hline & \multirow{4}{*}{ Año 2015} & PP: 48 escaños & \multirow{4}{*}{$\begin{array}{l}\text { Gobierna el PP mediante pacto } \\
\text { con Ciudadanos }\end{array}$} \\
\hline & & PSOE: 37 escaños & \\
\hline & & Podemos: 27 escaños & \\
\hline & & Ciudadanos: 17 escaños & \\
\hline \multirow{7}{*}{$\begin{array}{l}\text { Asamblea } \\
\text { Regional } \\
\text { de Murcia }\end{array}$} & \multirow{3}{*}{ Año 2011} & PP: 33 escaños & \multirow{3}{*}{ Gobierna el PP con mayoría absoluta } \\
\hline & & PSOE: 11 escaños & \\
\hline & & IU: 1 escaño & \\
\hline & \multirow{4}{*}{ Año 2015} & PP: 22 escaños & \multirow{4}{*}{$\begin{array}{l}\text { Gobierna el PP mediante pacto } \\
\text { con Ciudadanos }\end{array}$} \\
\hline & & PSOE: 13 escaños & \\
\hline & & Podemos: 6 escaños & \\
\hline & & Ciudadanos: 4 escaños & \\
\hline
\end{tabular}




\begin{tabular}{|c|c|c|c|}
\hline \multirow{7}{*}{$\begin{array}{l}\text { Parlamento } \\
\text { de La Rioja }\end{array}$} & \multirow{3}{*}{ Año 2011} & PP: 17 escaños & \multirow{3}{*}{ Gobierna el PP con mayoría absoluta } \\
\hline & & PSOE: 14 escaños & \\
\hline & & $\begin{array}{l}\text { PR: } 2 \text { escaños } \\
\text { (Partido Riojano) }\end{array}$ & \\
\hline & \multirow{4}{*}{ Año 2015} & PP: 15 escaños & \multirow{4}{*}{ Gobierna el PP con mayoría simple } \\
\hline & & PSOE: 10 escaños & \\
\hline & & Podemos: 4 escaños & \\
\hline & & Ciudadanos: 4 escaños & \\
\hline \multirow{9}{*}{$\begin{array}{l}\text { Cortes } \\
\text { de la } \\
\text { Comunitat } \\
\text { Valenciana }\end{array}$} & \multirow{4}{*}{ Año 2011} & PP: 55 escaños & \multirow{4}{*}{ Gobierna el PP con mayoría absoluta } \\
\hline & & PSOE: 33 escaños & \\
\hline & & $\begin{array}{l}\text { C. Compromís: } 6 \text { escaños } \\
\text { (Coalició Compromís) }\end{array}$ & \\
\hline & & $\begin{array}{l}\text { EUPV + ERPV: } 5 \text { escaños } \\
\text { (Esquerra Unida del País } \\
\text { Valenciá) }\end{array}$ & \\
\hline & \multirow{5}{*}{ Año 2015} & PP: 31 escaños & \multirow{5}{*}{$\begin{array}{l}\text { Gobierna el PSOE junto a Compromís } \\
\text { y Podemos }\end{array}$} \\
\hline & & PSOE: 23 escaños & \\
\hline & & Compromís: 19 escaños & \\
\hline & & Ciudadanos: 13 escaños & \\
\hline & & Podemos: 13 escaños & \\
\hline
\end{tabular}

Fuente: Elaboración propia a partir de los datos suministrados por la JEC.

\section{REFERENCIAS BIBLIOGRÁFICAS}

BARTLETT, B. (1997): “The end of the State Tax? Special Report", en Tax Notes, núm. 7, págs. 105-110.

BELTRAN, A. (2004): Partidos Políticos, Elecciones y Ciclos Económicos: el caso Español. Tesis doctoral. Universidad Pompeu Fabra. Departamento de Ciencias Sociales.

BLAIS, A.; NADEAU, R. (1992): "The Electoral Budget Cycle" en Public Choice, núm 74, págs. 389-403.

BOCCHIO, C. (2010): "Ciclo Político Económico. Una aplicación para Argentina", en Anales Asociación Argentina de Economía Política. Buenos Aires: Asociación Argentina de Economía Política. URL: https://aaep.org.ar/anales/ works/works2010/bocchio.pdf.

DOWNS, A. (1957): An Economic Theory of Democracy. New York: Harper and Row.

DURÁN, J. M.; ESTELLER, A. (2014): "La imposición sobre la riqueza en España", en Papeles de Economía Española, núm. 139, págs. 70-85.

ESTELLER, A.; DURÁN, J. M. (2012): "Introducción a la Imposición sobre la Riqueza", en Institut d'Economia (Universitat de Barcelona. URL: https://iieb.ub.edu/fase-1-introduccion-imposicion-sobre-la-riqueza/.

GUILLÉN, M. (2017): El Impuesto sobre Sucesiones y Donaciones. Comparativa entre las CC.AA y con respecto a la UE. Trabajo Fin de Grado. Madrid: Universidad Pontificia de Comillas.

JUNTA ELECTORAL CENTRAL (2018): "Elecciones autonómicas", Últimas elecciones celebradas. Fecha de consulta: 10-07-2018. URL: http://www.juntaelectoralcentral.es/cs/jec/elecciones.

LAGO, S. (2009): "La autonomía tributaria de las Comunidades Autónomas de régimen común: por qué y cómo avanzar" en Revista de Estudios Regionales, vol. Ext. VIII, págs. 83-95.

MEJÍA, P.; REYES, M. R.; RENDÓN, L. (2017): “¿Hay evidencia de ciclo político-económico en el empleo sectorial de México,1998-2013?”, en Contaduría y Administración, vol. 62, núm. 1, págs. 25-43. DOI: https://doi.org/10.1016/j. cya.2016.07.004.

NORDHAUS, W. (1975): "The political business cycle", en Review of Economic Studies, vol. 42, núm. 2, págs. 169190. DOI: $h$ ttps://doi.org/10.2307/2296528. 
NORDHAUS, W. (1989): "Alternative Approaches to Political Business Cycle", en Brookings Papers on Economic Activity, vol. 1989, núm. 2, págs. 1-68. DOI: https://doi.org/10.2307/2534461.

ORTEGA ALMÓN, M.; SÁNCHEZ MARTÍNEZ, M.; MARTÍN GARCÍA, L. (2015): "El Impuesto sobre Sucesiones y Donaciones en España: Competencia fiscal y desigualdades territoriales" en XII Jornadas Internacionales de Política Económica (JIPE). Toledo.

ORTEGA ALMÓN, M. A.; VÍLCHEZ ORTIZ, T.; ROJO GALLEGO-BURIN, A. (2020): "El Impuesto sobre Transmisiones Patrimoniales y Actos Jurídicos Documentados y el ciclo político: incidencia económica desde una doble perspectiva", en Revista de la Administración Local y Autonómica (REALA), núm. 13, págs. 131-151. DOI: https://doi.org/10.24965/reala.i13.10746.

PABLOS ESCOBAR, L. D. (2006): "Incidencia y Tipos Efectivos del Impuesto sobre el Patrimonio e Impuesto sobre Sucesiones y Donaciones", en Papeles de Trabajo, núm. 4. Madrid: Instituto de Estudios Fiscales.

PAMPILLÓN, R. (2006): “¿Qué es el ciclo político?" en Diccionario de Economía (Economy Weblog). URL: https:// economy.blogs.ie.edu/archives/2006/12/que_es_el_ciclo/.

RAMÍREZ, R.; ERQUIZIO, A. (2012): "Análisis del Ciclo Político Electoral a partir de variables de gasto público por entidad federativa en México, 1993-2009", en Paradigma Económico, año 4, núm. 2, págs. 5-27.

REAF-REGAF ASESORES FISCALES, CONSEJO GENERAL DE ECONOMISTAS (2012): Panorama de la Fiscalidad Autonómica 2012.

REAF-REGAF ASESORES FISCALES, CONSEJO GENERAL DE ECONOMISTAS (2013): Panorama de la Fiscalidad Autonómica y Foral 2013. URL: https://gestrisam.malaga.eu/portal/menu/seccion_0010/documentos/ Panorama_20CCAA_202013.pdf.

REAF-REGAF ASESORES FISCALES, CONSEJO GENERAL DE ECONOMISTAS (2014): Panorama de la Fiscalidad Autonómica y Foral 2014. URL: http://s01.s3c.es/imag/doc/2014-02-27/16.Fiscal.pdf.

REAF-REGAF ASESORES FISCALES, CONSEJO GENERAL DE ECONOMISTAS (2015): Panorama de la Fiscalidad Autonómica y Foral 2015. URL: http://www.lorenteylorente.es/2015/03/panorama-de-la-fiscalidadautonomica-en-2015/.

REAF-REGAF ASESORES FISCALES, CONSEJO GENERAL DE ECONOMISTAS (2016): Panorama de la Fiscalidad Autonómica y Foral 2016. URL: https://www.economistas.es/Contenido/REAF/Informes/REAFPanorama2016WEB.pdf.

REAF-REGAF ASESORES FISCALES, CONSEJO GENERAL DE ECONOMISTAS (2017): Panorama de la Fiscalidad Autonómica y Foral 2017. URL: https://www.economistas.es/Contenido/REAF/NOTAS\%20PRENSA/ PANORAMA\%2OFISCALIDAD\%20CCAA\%202017.pdf.

REAF-REGAF ASESORES FISCALES, CONSEJO GENERAL DE ECONOMISTAS (2018): Panorama de la Fiscalidad Autonómica y Foral 2018. URL: https://www.economistas.es/Contenido/Consejo/Estudios\%20y\%20 trabajos/REAF-\%20Panorama\%20de\%20la\%20Fiscalidad\%20CCAA-2018.pdf. 